\title{
Pediatric Type 2 Diabetes: Prevention and Treatment Through a Life Course Health Development Framework
}

\author{
Pamela Salsberry, Rika Tanda, Sarah E. Anderson, \\ and Manmohan K. Kamboj
}

\section{Introduction}

Estimates project that one in three US adults may have diabetes in 2050 (Boyle et al. 2010). The rates are even higher in some subgroups; for example, in Hispanic females it is 1 in 2 (Venkat Narayan et al. 2003). This problem is not limited to the USA. Shaw et al. 2010 estimate that $7.7 \%$

P. Salsberry, PhD, RN, FAAN ( $\varangle)$

College of Public Health, Division of Health Behavior, Health Promotion, Institute for Population Health, The Ohio State University, 1841 Neil Avenue, 353 Cunz Hall, Columbus, OH 43210, USA e-mail: Salsberry.1@osu.edu

R. Tanda, PhD, RN

College of Health Science and Professions,

Ohio University, Grover Center W133B, Athens, OH 45701, USA

e-mail: tandar@ohio.edu

S.E. Anderson, PhD

The Ohio State University, College of Public Health, 336 Cunz Hall, 1841 Neil Avenue, Columbus, OH 43210, USA

e-mail: sanderson@cph.osu.edu

M.K. Kamboj, MD

The Ohio State University, College of Medicine, Endocrinology, Metabolism and Diabetes,

Nationwide Children's Hospital,

700 Children's Drive (ED425), Columbus, OH 43205, USA

e-mail: Manmohan.Kamboj@Nationwidechildrens.org or 434 million adults will have diabetes by 2030 worldwide (Shaw et al. 2010). Until very recently, type 2 diabetes mellitus (T2DM) was a disease diagnosed in adults, but as the childhood obesity epidemic has spread in both magnitude and severity, the diagnosis of T2DM in adolescents and young adults has become more common. The prevalence of prediabetes in 12-19 years, estimated using National Health and Nutrition Examination Survey (NHANES) data, increased from $9 \%$ in $1999-2000$ to $23 \%$ in $2007-2008$ (May et al. 2012). Analyses using data from the SEARCH for Diabetes in Youth Study (SEARCH) indicate a $30.5 \%$ overall increase in the prevalence of T2DM in children/adolescents from 2001 to 2009 (Dabelea et al. 2014). Because of the newness of this diagnosis in children and adolescents, very little is known about the natural history of the disease, and it will likely take decades to fully understand the determinants and consequences of this new epidemic. Early indicators suggest that the disease may be more severe (Elder et al. 2012) and more difficult to manage when diagnosed in adolescents (Zeitler et al. 2012).

A recent analysis estimates that adolescents with T2DM will lose approximately 15 years of life and will experience severe and chronic complications by their $40 \mathrm{~s}$ as a result of the disease (Rhodes et al. 2012). The mean direct cost for medical care for a man diagnosed with T2DM for less than 15 years is estimated at $\$ 2465$. The economic burden of T2DM rises significantly as the 
years with disease increase. For those with disease 15 years or more, the costs are estimated to be $10-50 \%$ higher. This grim forecast highlights that not only will the disease burden be significant but the economic burden will be high in youth diagnosed with T2DM ( $\mathrm{Li}$ et al. 2013). Metabolic comorbidities occur with alarming frequency (West et al. 2009). Within the SEARCH study, a significant portion of adolescents with T2DM had hypertension, high LDL cholesterol, or high triglycerides (Lawrence et al. 2009a; Mayer-Davis et al. 2009). It is clear that there is much to do to understand the epidemic, to determine effective prevention strategies, and to develop interventions for those diagnosed with the disease. It is also clear from what we are learning that preventive and treatment strategies need to begin early.

The risk for a child developing T2DM begins in utero. Individual health development trajectories emerge from this starting point and are the result of factors that accumulate across time and/or are the result of biological conditioning during sensitive periods of development. Understanding how these trajectories emerge, and which factors and events result in disease-causing pathways, is key to not only understanding the onset and variable natural history of the disease but in determining ways to prevent and treat it. There is an extensive and emergent body of literature that examines the mechanisms, pathways, and determinants of T2DM in children and adolescents. Genetic and epigenetic mechanisms are clearly a part of the story, but several studies also demonstrate the influence and importance of the social context on developing biological processes (Kempf et al. 2008). These include behaviors and psychological stressors nested within families, neighborhoods, and communities. Consistent with the principles of life course health development that are presented by Halfon and Forrest (2017), there is a growing consensus that T2DM is the result of the multilevel interaction of genetic, behavioral, social, and economic factors with the timing, sequence, and dose of exposure central to long-term outcomes.

A life course health development approach that details risks and protective factors, as well as preventive and treatment strategies, contextualized within the developmental stage of the child, is required. While one's genetic code may establish susceptibility toward T2DM development, its development is the result of a complex process of person-environment interactions that are multidimensional, multidirectional, and multilevel. A major aim of this chapter is to demonstrate that a life course health development approach to pediatric T2DM is critical to the development of a sound national strategy to prevent and treat T2DM in children. We review major factors known to influence the development of pediatric T2DM and track these across childhood. This set of factors will likely change over the next decade as our understanding of disease mechanisms deepens, but what will not change is the importance of placing these factors into context and recognizing that T2DM development is highly sensitive to the timing and social structuring of multiple environmental exposures. Research recommendations relevant to the field of maternal and child health regarding T2DM will be discussed through a life course lens. This chapter is organized around four key developmental stages: preconception and intrauterine life, infancy, childhood (early and middle), and adolescence. These health development stages unfold against the "backdrop" of each child's genetics, race/ethnicity, and family economic status.

\section{The Backdrop}

\subsection{Genetics}

Having a relative with T2DM is an established risk factor for the disease (Rosenbloom et al. 1999). Through a series of twin studies, heritability of fasting glucose levels has been estimated to range from $38 \%$ to $51 \%$ (Katoh et al. 2005; Snieder et al. 1999). Heritability is a population parameter that measures the fraction of variation, i.e., fasting glucose levels, among individuals in a population that is attributable to their genotypes (Visscher et al. 2008). At the individual level, a positive family history of T2DM has been associated with reduced insulin sensitivity at younger ages in children and adolescents when compared 
with children with no family history (Arslanian et al. 2005). There is a $40 \%$ increased lifetime risk for T2DM for children if one parent has T2DM; this increases to $70 \%$ if both parents have T2DM (Groop and Tuomi 1997). Studies have found that as many as $80 \%$ of youth with T2DM have a close relative with diabetes (Arslanian et al. 2005; Copeland et al. 2011).

Most of the genetic studies of T2DM have been carried out with adults; genetic studies of T2DM in children and youth are limited because of low number of subjects (Morgan 2012). An exception to this is a large meta-analysis that combined data from 6 European cohorts to test whether associations of common genetic variants identified for fasting glucose or insulin levels in nondiabetic adults were detectable in healthy children and adolescents. They found that the majority of novel fasting glucose loci identified in genome-wide associations studies (GWAS) in adults were detectable in childhood and at similar effect sizes (Barker et al. 2011). Work is progressing to examine whether associations between adult-identified susceptibility genes with T2DM hold in pediatric T2DM. For example, transcription factor 7-like 2 (TCF7L2) has been found to be associated with an increased risk of T2DM in African-American youth but not in non-Hispanic whites (Dabelea et al. 2011).

There is clear evidence that genetics plays a role in childhood susceptibility to T2DM, but significant research is needed. This research will require substantial collaboration across sites to achieve sample sizes large enough to test hypotheses. While progress is being made in elucidating underlying gene variants in adults, testing to determine if the same variants are operating in children and adolescents is required (Morgan 2012).

\subsection{Prevalence and Incidence of T2DM Related to Age, Race, and Ethnicity}

The prevalence of T2DM among children has risen with population increases in obesity, but compared to adolescents, T2DM in preadolescent children occurs less frequently. The highest rates are noted for adolescents aged 15-19 years, while incidence in children below 10 years in age is low. These results come from the SEARCH study, a multiethnic, population-based study designed to estimate rates of diabetes (both type 1 and type 2) based upon health-care provider assessment and in a subpopulation with further blood analyses. Data from SEARCH indicated a prevalence of diagnosed T2DM among 10-14year-olds of 0.23 cases per 1000 children in 2009, up from 0.15 per 1000 in 2001 (Dabelea et al. 2014). Comparable prevalence estimates for adolescents (15-19 years) in 2001 and 2009 were respectively 0.54 and 0.68 per 1000 (Dabelea et al. 2014). Data from 1999 to 2010 NHANES, representative of US youth 12-19 years, indicated a total prevalence of T2DM of 0.36 per 1000 (Demmer et al. 2013). This estimate combines diagnosed and undiagnosed cases of T2DM, with approximately $1 / 3$ of the total being undiagnosed but having a fasting glucose level of $\geq 126 \mathrm{mg} / \mathrm{dL}$ (Demmer et al. 2013). The prevalence of pediatric T2DM is higher for females and among minorities in the USA (Dabelea et al. 2014). SEARCH researchers modeling T2DM incidence by age and race/ethnicity report increasing incidence during the elementary school years with a peak in incidence at approximately age 14 years for all racial-ethnic groups (Imperatore et al. 2012). At any age, the incidence of T2DM for African-American, Hispanic, and Asian/Pacific Islander youth is higher than for non-Hispanic whites (Imperatore et al. 2012; Dabelea et al. 2007), and the incidence for children under 10 years old is very low (annual incidence $<1$ per 100,000) (Dabelea et al. 2007). However, because T2DM develops gradually, can be asymptomatic, and may be misdiagnosed as type 1 diabetes mellitus (T1DM) in children, population estimates of prevalence and incidence must be interpreted cautiously (Amed et al. 2010a).

\subsection{Economic Status}

Data on the relationship between economic status (of parents) and children and adolescents diagnosed with T2DM are limited, but there are 
indications of a positive correlation. The treatment options for T2DM in adolescents and youth study (TODAY Study) found that $41.5 \%$ of their subjects came from households with an annual income of less than $\$ 25,000$, and $26.3 \%$ were in families in which the highest education level of the parent/guardian was less than a high school degree (Copeland et al. 2011). The association of economic status measured by educational level, occupation, and income with T2DM in adults has been studied extensively and likely offers clues to risk in children and adolescents. A systematic review and meta-analysis that was global in scope found associations with low levels of education (relative risk $(\mathrm{RR})=1.41,95 \%$ CI: $1.28-1.51)$, with occupation $(\mathrm{RR}=1.31,95 \% \mathrm{CI}$ : $1.09-1.57)$, and with low income $(\mathrm{RR}=1.31,95 \% \mathrm{CI}$ : 1.09-1.57). While the data were limited from middle- and low-income countries in this study, the increased risks were independent of the income levels of countries (Agardh et al. 2011). Another systematic review examining childhood socioeconomic status (SES) as a risk for T2DM found a strong relationship; although this relationship was attenuated by adult SES, a significant relationship remained (Tamayo et al. 2010). Parental education has been found to be associated with insulin resistance in the CARDIA study participants, and the association differed by race and gender. Low parental education was associated with greater insulin resistance in AfricanAmerican and white females and in African-American males, but not in white males (Tamayo et al. 2012). Smith et al. 2011 found similar results in the Framingham Offspring Study where an inverse relation between cumulative economic status and T2DM in women, but not men, was noted (Smith et al. 2011). These results highlight why untangling the pathways for risk will be difficult.

\subsection{Social (Psychological) Stressors}

There is strong evidence that acute or chronic stress during critical periods in early life, childhood, and/or adolescence has long-term risks for altered metabolic function including the develop- ment of T2DM (Pervanidou and Chrousos 2012). Obesity likely mediates this relation brought on by unhealthy behaviors related to eating and activity patterns as coping mechanisms for chronic stress. Furthermore, chronic stress leads to the dysregulation of the hypothalamicpituitary-adrenal (HPA) axis, with increased cortisol, catecholamine, and elevated insulin concentrations (Pervanidou and Chrousos 2011). Key stressors in children are recognized as those related to the creation of a safe, stable, and nurturing environment, and when these are disrupted, the child's long-term health suffers (Shonkoff and Garner 2012).

\subsection{Summary}

These "backdrop" factors are the platform upon which health develops and emerges over time, influenced by dynamic interactions at multiple levels (biological, behavioral, social/cultural) at sensitive periods transacting simultaneously. The next sections illustrate this principle by highlighting key factors within developmental stage that have been linked to pediatric T2DM.

\section{Preconception and Intrauterine Life}

Over the last 20 years, a significant body of evidence from epidemiological and animal studies has established a strong link between the intrauterine environment and long-term health (Dyer and Rosenfeld 2011; Gluckman et al. 2008; McMillen and Robinson 2005; Sebert et al. 2011; Sinclair et al. 2007). The notion of biological embedding is now widely accepted, even though the mechanisms are not completely understood (Tarry-Adkins and Ozanne 2011). Maternal nutritional status, gestational diabetes, high levels of maternal stress, hypoxia/placental insufficiency, and environmental toxins have been associated with the development of T2DM in children and adolescents (Warner and Ozanne 2010; Boekelheide et al. 2012). Furthermore, the relationship of these high-risk maternal factors to 
intrauterine growth restriction (IUGR) and small-for-gestational-age (SGA) newborns with their predisposition for obesity, insulin resistance, and T2DM later in life has been established as well. These factors are briefly reviewed below. Several excellent papers review the underlying mechanisms of these relationships in greater depth (Dyer and Rosenfeld 2011; Armitage et al. 2004; Berends and Ozanne 2012; Martin-Gronert and Ozanne 2012; Thayer et al. 2012; Prince et al. 2014).

\subsection{Maternal Nutrition: Prior to and During Pregnancy}

\subsubsection{Maternal Under Nutrition}

A series of studies linking low birth weight, maternal undernutrition, and the development of cardiovascular disease has fueled much work on the impact of caloric restriction on the developing fetus (Hales and Barker 2001; Barker et al. 1993). Animal studies have found endocrine and metabolic abnormalities associated with food restrictions (Warner and Ozanne 2010). Data suggest that undernutrition alters the structure and/or function of the developing endocrinemetabolic axis, leading to an insulin resistance and energy conservation in light of reduced calories. An overactivation of the HPA axis leads to increased cortisol levels in growth-restricted fetuses, a situation that mimics chronic stress (Kanaka-Gantenbein 2010; Kapoor et al. 2006). The effects of the undernutrition seem to depend on the timing and extent of the deprivation. In a rodent study, a 50\% caloric restriction at the end of the fetal period resulted in reduced $\beta$-cell mass (Bertin et al. 2002), and if the caloric restriction continued through early life, the reduction in $\beta$-cell mass was permanent (Garofano et al. 1998). Furthermore, the type of diet seems to be important as well. Because of the importance of amino acids in fetal development, studies on the effects of low-protein diets on fetal growth have been pursued with high interest (FernandezTwinn et al. 2005). Studies have shown that when dams were fed a low-protein diet, the results were growth-restricted pups, and if the maternal diets remained low protein during suckling, the growth restriction was permanent. Most importantly, these offspring then went on to develop glucose intolerance and T2DM (Hoet et al. 1992).

\subsubsection{Maternal Overnutrition}

Maternal obesity at the time of pregnancy is known to be associated with a greater risk for child obesity (Salsberry and Reagan 2005), placing them at increased risk for the development of T2DM. Fetal overnutrition has also been associated with insulin resistance and adult diabetes (Armitage et al. 2008). In animal studies, offspring born to obese maternal rats had higher fat-to-lean ratios at birth, and by 3 months of age, these pups were insulin resistant (Samuelsson et al. 2008). When pregnant dams are fed a highfat content, the offspring are noted to develop a phenotype resembling the human metabolic syndrome (Armitage et al. 2008).

\subsection{Maternal Stress}

Increased maternal stress is associated with adverse birth outcomes, in particular low birth weight and preterm birth (Christian 2012). Studies demonstrate that maternal exposure to glucocorticoids reduces birth weight in sheep and rats (Tarry-Adkins and Ozanne 2011). Meaney et al. (2007) have suggested that these birth outcomes are mediated by effects on the HPA axis. Stressors in the environment alter maternal physiology and behavior, which then programs HPA activity in the offspring (Meaney et al. 2007). These changes have been linked to the development of T2DM and other components of the metabolic syndrome in the offspring (Brunton 2010).

\subsection{Maternal Hypoxia/Placental Insufficiency}

Fetal oxygenation is also an independent risk factor for fetal growth abnormalities and long-term development of T2DM. Reduction in fetal oxygenation has also been associated with IUGR, a known risk factor for metabolic syndrome. 
Multiple underlying pathophysiological reasons for fetal hypoxia include placental insufficiency, uterine placental ligation, and smoking. These effects all result in IUGR (Tarry-Adkins and Ozanne 2011).

\subsection{Environmental Exposures}

Exposures to environmental toxins during pregnancy are under increased scrutiny as the evidence builds suggesting significant life course health affects with early-life exposures to a range of chemicals (Thayer et al. 2012). In particular, nicotine, arsenic, and endocrine disrupting chemicals (EDC) are tied to metabolic outcomes. For example, high levels of arsenic exposure have been linked to T2DM in adults, and there is some suggestion that even low doses may also confer an increased T2DM risk (Navas-Acien et al. 2008; Maull et al. 2012). The causal mechanisms include altered glucose metabolism, insulin resistance, and obesity as a result of exposure (Seki et al. 2012). Exposure to EDC, particularly bisphenol A (BPA), is thought to lead to functional changes in gene expression and increased risk for development of obesity and T2DM (Barouki et al. 2012; Liu et al. 2013). This is an area of intense activity that will likely result in significant new knowledge over the next decade.

\subsection{Microbiome}

There is growing recognition of the importance of the human microbiome in pediatrics (Johnson and Versalovic 2012). During pregnancy a woman's microbiome undergoes significant change from the first to third trimester, changes thought to be beneficial to the mother and the establishment of the neonatal microbiome (Prince et al. 2014; Koren et al. 2012). The infant's microbiota is influenced by the mode of delivery, with colonization in vaginally delivered newborns a function of maternal vaginal and intestinal microbiota, while cesarean delivered newborns exhibit the microbiome of the maternal skin microbiota.
The infant's environment and nutrition further influence the infant's developing microbiome (Johnson and Versalovic 2012). These environmental influences on the developing microbiome are critical, as the microbiome is thought to play a role in health and disease (Cenit et al. 2014; Devaraj et al. 2013). Evidence from research in adults suggests that the microbiome plays a critical role in T2DM. Ongoing research is beginning to demonstrate implications for prevention and treatment of metabolic conditions based upon knowledge of the microbiome; extending this work to children is of high importance (Szajewska 2013; Versalovic 2013).

\subsection{Gestational Diabetes (GDM)}

GDM represents a form of impaired glucose tolerance that is first recognized during pregnancy. Insulin resistance normally occurs in pregnancy. This allows the metabolic needs of the fetus to be met, while an increased maternal insulin secretion compensates for the insulin resistance. But in GDM, this increased resistance is coupled with a failure of increased insulin secretion, resulting in hyperglycemia (Battista et al. 2011). GDM is harmful to the mother and to the fetus. GDM has been shown to alter pancreatic development and insulin sensitivity in the fetus (Warner and Ozanne 2010). Fetal growth is often affected, resulting in macrosomia or large-for-gestational-age infants (Dyer and Rosenfeld 2011). The Hyperglycemia and Adverse Pregnancy Outcome (HAPO) study found a strong linear relation between fasting glucose and post challenge glucose with macrosomia and neonatal adiposity (Metzger et al. 2008). Macrosomic infants born to diabetic mothers have been found to be more glucose intolerant between the ages of 10-16 years, are more likely to be obese, and are at a greater risk for T2DM (Silverman et al. 1998). Because of methodological differences in current studies, the long-term effect of GDM on child outcomes is not fully understood, but studies do suggest that increased rates of obesity, T2DM, and other cardiovascular conditions may result (Kim et al. 2011; Simeoni and Barker 2009). 
Screening and Diagnosis Given the convincing evidence that diabetes and gestational diabetes are harmful to both the mother and fetus, considerable effort has been directed toward establishing consensus criteria for the diagnosis of diabetes in pregnancy. There is controversy over the "correct" diabetes threshold, that is, the level at which maternal blood glucose conveys a significant risk to the fetus. The HAPO study, a multisite and multinational study, was designed to address some of these questions. HAPO study results showed a linear relation between increasing levels of fasting and 1 and 2 hour plasma glucose levels post a $75 \mathrm{~g}$ oral glucose tolerance test (OGTT) on the primary study outcomes, including birth weight above 90th percentile, cord blood C-peptide level above the 90th percentile, primary cesarean delivery, and neonatal hypoglycemia (Hadar and Hod 2010). These results have led to guidelines issued in 2010 by the International Association of Diabetes and Pregnancy Study Groups (IADPSG) for the detection and diagnosis of hyperglycemic disorders in pregnancy. These guidelines include the determination of the diabetes status of the pregnant woman at the first prenatal visit. Following these guidelines is expected to increase the number of all women with diabetes during pregnancy. These guidelines, however, remain controversial (Moses 2010). There are concerns over increasing costs associated with the identification of a greater number of women with diabetes resulting in an increased number of women receiving treatment.

The American College of Obstetricians and Gynecologists and the National Diabetes Education program have joined together in a call for action, specifically recommending follow-up testing during the postpartum period in women who experienced GDM. Currently only approximately one-half of these women are tested. Recommendations include the following: If the postpartum test is normal, retest every 3 years and at the first prenatal visit for subsequent pregnancies. If prediabetes is diagnosed at the post- partum check, then the recommendation is to test annually (Gabbe et al. 2012).

Treatment Intrauterine conditions are being targeted in the HAPO study. The initial results showed that close control of glucose improved birth outcomes, leading to the new recommendations for the diagnosis and classification of hyperglycemia during pregnancy (Metzger et al. 2010). The HAPO study is also following the outcomes in children born to women with GDM; this longitudinal follow-up may yield important insights for the health of the offspring as well. Early results, however, on offspring at ages 4 and 5 show no difference in body mass index (BMI) in the treatment group (Gillman et al. 2010). Further work with longer follow-up is required to determine if there are latent effects of treatment that will potentially influence outcomes at a later age.

\subsection{Summary}

Intrauterine life is a sensitive period for T2DM risk development. Building upon the backdrop of genetic susceptibility and within the social and economic context of the mother, the fetus develops an underlying propensity toward T2DM development. Much of this comes through epigenetic changes influenced by maternal nutrition, life stressors, chemical exposures, and maternal behaviors. The occurrence of higher levels of risk is strongly correlated with maternal economic disadvantage and the result of molecular, physiological, behavioral, cultural, and evolutionary processes that interact across time and space. Consistent with the principles of life course health development (LCHD), development of a phenotype at high risk for T2DM development is thus the result of person-environment interactions that are multidimensional, multidirectional, and multilevel, which are highly sensitive to the timing and social structure of environmental exposures. 
4

\section{Infancy}

\subsection{Feeding}

Multiple advantages of breastfeeding are well accepted (American Academy of Pedicatrics 2012; James and Lessen 2009), but clarifying the relationship between breastfeeding and future metabolic function is not simple and requires consideration of multiple factors that have effects over one's life course. Controlling social and environmental factors between infancy and some later age is difficult because information for such a long interval is often missing. Despite the limitations, there are several studies that have examined infant feeding type or breastfeeding duration and their relation to dietary habits or cardiometabolic risks. For example, a study that used the Hertfordshire cohort has found an independent association between exclusive breastfeeding (vs. mixed or bottle-feeding) and adherence to healthy dietary recommendations and less intake of processed meat in middle to late adulthood (Robinson et al. 2013). Socioeconomic factors were not associated with the dietary recommendation adherence. The authors speculate breast milk may have provided significant impact on dietary flavor learning during infancy.

In a recent study by Martin et al. (2014), the relationship between cardiometabolic risks and long-term exclusive breastfeeding was examined. This study was a follow-up study of a randomized control study where one group of new mothers was encouraged to undertake exclusive breastfeeding and the other nonexclusive breastfeeding. While the original intervention significantly prolonged breastfeeding duration and exclusiveness, the intervention effect did not influence cardiometabolic factors, such as blood pressure, fasting glucose, insulin, insulin resistance, and adiponectin, when children were at age 11.5 years. A previous follow-up study of this cohort also failed to show intervention effects on anthropometry (height, weight, BMI, and skinfold) and blood pressure at age 6.5 years (Kramer et al. 2009).

Investigating the effects of breastfeeding is complex as there are likely multiple biological and behavioral ways that breastfeeding may influence the infant's health development. Nutrition-focused research studies that examine the importance of the nutrients within breast milk are ongoing. But there are also suggestions that breastfeeding may impact an infant's ability to self-regulate behavior. For example, Taveras et al. (2004), using the US mixed-race cohort, have found that restrictive feeding style is associated with bottle-feeding and shorter breastfeeding duration, which could disrupt the infant's ability to self-regulate feeding behavior. Maternal restrictive feeding style was also found to be associated with increased child's weight for age at 18 months among an African-American sample (Thompson and Bentley 2013).

There has been particular interest in the effects of breastfeeding on children who are exposed to maternal diabetes in utero. The evidence is mixed regarding the effects of breastfeeding among offspring of diabetic mothers (ODM) and development of obesity and T2DM during childhood. A study from Germany found that high consumption of breastmilk during the first 7 days of life among ODM may pose deleterious effects on body weight and glucose tolerance measured at age 2 years (Plagemann et al. 2002). These authors suggest that certain substances contained in early milk of mother's with diabetes may program for metabolic dysregulation in their offspring.

In the Nurses' Health Study II (Mayer-Davis et al. 2006), researchers found that exclusive breastfeeding compared to exclusive formula feeding, or longer duration of breastfeeding (>9 months) compared to never breastfed, was associated with lower odds of being overweight at ages 9-14 years, controlling for child's age, gender, and pubertal development. However, further controlling for other maternal and child factors resulted in null association, and a separate analysis for ODM did not reach statistical significance. A case control study using the SEARCH participants found that longer duration of breastfeeding resulted in a reduction in T2DM, controlling for maternal, child's, and social factors. When the child's weight (measured using BMIz) was included in the analysis, the association was attenuated to null, suggesting that the 
child's BMIz may mediate the pathway to a diagnosis of T2DM (Mayer-Davis et al. 2008).

The mechanisms involved in the effects of breastfeeding on child's future weight status or risks for T2DM are unclear. However, insulin and other metabolic hormones that are present in breast milk likely play some role. Insulin is present at more than threefold concentration in early milk collected within the first weeks of the postpartum period than in mature milk collected 3 months postpartum (Ley et al. 2012). The insulin concentration in early milk does not appear to be affected by the mother's gestational diabetes status. While the insulin concentration in mature milk of nondiabetic women is not different from that of women with GDM (Ley et al. 2012), maternal prenatal metabolic indicators, such as BMI, fasting glucose, insulin resistance, insulin sensitivity, and adiponectin levels, can predict insulin concentration in mature milk (Ley et al. 2012; Whitmore et al. 2012).

Other research efforts have been focused on infant feeding practices, such as timing of solid food introduction and amount of sugar-sweetened drink during infancy and early childhood, and their effects on childhood obesity development (Gaffney et al. 2012). Another area is investigation of micro- and macronutrient constituents of breast milk. A randomized clinical trial demonstrated that health modifications made to the diets of pregnant and lactating women improved infant metabolic health (Aaltonen et al. 2011). More research is needed to investigate how infant feeding may influence metabolic health development over the life course. An excellent review article summarizes the critical next questions in lactation and neonatal nutrition, providing a road map for this necessary research (Neville et al. 2012).

\subsection{Infant Growth Patterns}

Several studies (Fabricius-Bjerre et al. 2011; Ekelund et al. 2007; Eriksson et al. 2006) highlight significant associations between infant/ childhood growth patterns and development of T2DM and later cardiovascular disease. Because growth is orchestrated by a complex series of interactions between growth hormone, sex steroids, and insulin, tracking growth over time is an important global health measure. Understanding high-risk growth patterns may assist in earlier identification of high-risk children with the potential to begin interventions at an earlier age. The Helsinki Birth Cohort Study (HBCS) 19341944 has shown that a small body size at birth with thinness during the first year followed by higher BMIs later in childhood is associated with the development of T2DM (Eriksson 2006). Also, this study found that an early age at adiposity rebound was associated with a markedly increased risk of T2DM in adulthood (Eriksson 2011). An important recent finding suggests that breastfeeding may alter childhood growth even in children exposed to overnutrition during the pregnancy. In the Exploring Perinatal Outcomes among Children (EPOCH) study, breastfeeding was associated with long-term effects on childhood BMI growth extending into late childhood. Slower BMI growth velocity was seen among adequately breastfed (breastfeeding $>6$ months) children compared with infants who had low breastfeeding status, and these benefits lasted through age 9 years (Crume et al. 2012).

\subsection{Sleep Duration}

Shortened sleep duration is suggested as a risk factor for obesity, insulin resistance, and Type 2 diabetes among adults. Long-term effects of shortened sleep during infancy on metabolic function are unknown. A limited number of studies that examined the relationship between sleep duration during infancy and subsequent obesity in early childhood have produced conflicting results. For example, studies of US children (Taveras et al. 2008, 2014) have found chronic sleep curtailment from infancy to age 7 years was associated with increased BMI z-scores. Because short sleep hours were associated with longer TV viewing time, the investigators suggested the screen time as one of the potential pathways for the association. Similarly, Bell and Zimmerman (2010) using sample from the Panel Survey of Income DynamicsChild Development Supplement, reported that 
shortened night time sleep (less than 9 hours) during early childhood (ages 0-59 months) but not during school age was associated with increased likelihood of being overweight or obese at followup at age 5-10 years. Both US studies include relatively large number of minority population $(30-50 \%)$ whose nighttime sleep is on average shorter than white children. However, studies of Dutch children and Australian children have shown no such association (Hiscock et al. 2011; Klingenberg et al. 2013). The latter two studies utilized objective measures of sleep duration such as actinography, while the US studies have relied on parental report. Improvement in measurement of child's sleep duration and other behavioral markers in longitudinal studies are needed to advance the knowledge in this area.

\subsection{Parenting and Postpartum Depression}

The impact of maternal postpartum depression on parenting is significant during the first year of life. Mothers who suffer from postpartum depression may lack responsiveness to infant cues for hunger or satiety. However, the studies examining the association between maternal depressive symptoms and child weight status have produced mixed results. Several studies conducted in the USA have shown the association between maternal postpartum depressive symptoms and inappropriate parenting practices such as shorter or less intense breastfeeding (McLearn et al. 2006; Gaffney et al. 2014), inappropriate early feeding practices (Gaffney et al. 2014), and fewer healthy interactions with infants (McLearn et al. 2006). Exposure to chronic maternal depressive symptoms has also been associated with increased risk of childhood overweight (Wang et al. 2013). Cumulative exposure to maternal depressive symptoms in early infancy can lead to disruption of behavioral and metabolic cues for sensation of hunger and satiety. A study involving five European countries, however, has shown no relationship between maternal depressive symptoms and adiposity measures at age 24 months (Grote et al. 2010). The investigators of the latter study noted that prevalence of high depressive symptom scores differed significantly by the participating countries, and therefore, the instrument to measure depressive symptoms used in this study may not be comparably used by the participants across different study sites. More prospective cohort studies focused on the relationship between infant/child development and maternal lifestyles as well as infant's surrounding environment are needed. Cohort studies such as the Amsterdam Born Children and their Development (ABCD) study (van Eijsden et al. 2011) may provide further knowledge on this area.

\subsection{Summary}

Infant development occurs within a context of "backdrop" factors and as an extension of what has happened during the prior period (fetal life). Because evolutionary life-history theory suggests that development during fetal life prepares the neonate for a particular external environment, when conditions in utero match the conditions in infancy, development unfolds as an extension of pathways begun in utero. When a mismatch occurs between these environments, aspects of development may be compromised. This may be the case when undernutrition in fetal life is followed by an abundance of nutrients postnatally, a particularly risky circumstance for metabolic health. The important point is that infant health development must be seen as conditioned by the interaction of processes and conditions during intrauterine life, and that this wider lens brings into sharper focus the multiple interacting risks contributing to the development of T2DM. Our examinations of how experiences in infancy feed forward into this continuously evolving health developmental process suggest that long-term health behaviors are beginning to be set through complex transactions between maternal behaviors and preferences regarding feeding and sleep (both of which are influenced by the mother's own environment and psychological state) and the infant's developing behavioral response patterns. 
5

\section{Childhood}

\subsection{Childhood Overweight and Obesity}

Almost all children and adolescents with T2DM are also overweight or obese, and excess adiposity, particularly visceral adiposity, is associated with insulin resistance (Dabelea et al. 2007; Haines et al. 2007; Amed et al. 2010b). Studies with US and Canadian youth have found that $75-95 \%$ of those with T2DM are obese (BMI percentile $>95$ th for age and sex) (Mayer-Davis et al. 2009; Amed et al. 2010b; Liu et al. 2009; Lawrence et al. 2009b; Bell et al. 2009). Another study in obese children found that $25 \%$ of obese children $4-10$ years of age and $21 \%$ of 11-18 years of age were found to have an impaired glucose tolerance. Silent T2DM was identified in $4 \%$ of the obese adolescents (Sinha et al. 2002). Researchers in the UK using the International Obesity Task Force (IOTF) cut point for defining obesity (which is higher than the US reference (Rolland-Cachera 2011)) found that $83 \%$ of youth with T2DM were obese (Haines et al. 2007). These results clearly point to the importance of understanding the underlying factors that contribute to childhood obesity, and also point toward the complex path that underlies the development of T2DM. Further understanding of how multiple factors interact, with a key emphasis toward the timing of these factors in reference to the life course is needed (Ong 2010; Tounian 2011).

\subsection{Impaired Glucose Tolerance and Progression to T2DM}

Obese children may have deficits in glucose regulation that predict future T2DM, as well as less favorable risk factor profiles for cardiovascular disease (West et al. 2009; Burns et al. 2014). Evidence of impaired glucose tolerance, elevated fasting glucose, insulin resistance, and/or previously undiagnosed "silent" T2DM has been documented in multiple samples of obese youth
(Wabitsch et al. 2004; Sinha et al. 2002; Morrison et al. 2012). Morrison et al. (2012) studied 259 overweight and obese children and adolescents (aged 5-17 years) who were seeking weight-loss treatment and found that $>20 \%$ had prediabetes-impaired glucose tolerance as measured by an oral glucose tolerance test or elevated fasting glucose (Morrison et al. 2012). Among these youth with prediabetes, a majority with impaired glucose tolerance did not have elevated fasting glucose levels (Morrison et al. 2012), which is consistent with findings from an Italian study (Morandi et al. 2014). The current American Diabetes Association (ADA) guidelines (American Diabetes Association 2010) recommend that overweight children $\geq 10$ years or pubertal with two or more additional risk factors for T2DM have their fasting glucose measured (see Table 1). ADA guidelines do not recommend screening youth with an oral glucose tolerance test. Morrison et al. found that the sensitivity and specificity of the ADA criteria to identify youth with prediabetes were respectively 39\% and $70 \%$. Furthermore, in their sample the prevalence of prediabetes in children 5-9 years old was not significantly different from that of youth $\geq 10$ years old (Morrison et al. 2012). Some evidence indicates that elevated fasting triglycerides may help to identify obese children and adolescents who would benefit from an oral glucose tolerance test (Morrison et al. 2012; Morandi et al. 2014). More longitudinal studies of children at risk for T2DM are needed to elucidate the natural history and progression of the disorder. In a sample of 117 obese children and adolescents (4-18 years) in which two oral glucose tolerance tests were administered between 18 and 24 months apart, Weiss et al. 2005 found that of 38 youth with impaired glucose tolerance at the first time point, 8 developed T2DM, 10 still had impaired glucose tolerance, and $15(46 \%)$ had normal glucose tolerance at the second time point (Weiss et al. 2005). Among the 84 youth with normal glucose tolerance initially, 8 had impaired glucose tolerance at the follow-up assessment (Weiss et al. 2005). Progression from prediabetes to T2DM has been studied among adults (Morris 
Table 1 Summary of screening guidelines for T2DM: Childhood overweight and obesity

\begin{tabular}{|c|c|c|c|}
\hline & Year & Recommendations & Other risk factors \\
\hline \multicolumn{4}{|l|}{ Diabetes screening } \\
\hline $\begin{array}{l}\text { Expert Committee } \\
\text { (Barlow 2007) }\end{array}$ & 2007 & $\begin{array}{l}\mathrm{BMI}>85 \text { th } \% \text { and aged } \geq 10 \text { years } \\
\text { with } \geq 2 \text { other risk factors FGT or } 2 \mathrm{~h} . \\
\text { GTT; BMI } \geq 95 \text { th } \% \text { and } \\
\text { aged } \geq 10 \text { years FGT every } 2 \text { years }\end{array}$ & $\begin{array}{l}\text { Parental obesity } \\
\text { Family history } \\
\text { Current lifestyle } \\
\text { BMI trajectory CVD risk factors } \\
\text { (HBP, cholesterol) }\end{array}$ \\
\hline $\begin{array}{l}\text { ADA (Amercian Diabetes } \\
\text { Association 2000) }\end{array}$ & 2012 & $\begin{array}{l}\text { BMI }>85 \text { th } \% \text { or weight }>\% \text { of ideal } \\
\text { for height with } \geq 2 \text { other risk factors } \\
\text { screened every } 3 \text { years beginning at } \\
\text { age } 10 \text { years or onset of puberty, } \\
\text { whichever is earlier. Testing done } \\
\text { every } 2 \text { years }\end{array}$ & $\begin{array}{l}\text { Family history of T2DM in first or } \\
\text { second-degree relatives } \\
\text { Certain race/ethnic groups }{ }^{\mathrm{b}} \\
\text { Signs of insulin resistance or } \\
\text { conditions associated with insulin } \\
\text { resistance (AN, HTN, dyslipidemia, } \\
\text { PCOS, SGA) } \\
\text { Maternal diabetes or GDM }\end{array}$ \\
\hline $\begin{array}{l}\text { ISPAD }^{\text {a }} \text { (International } \\
\text { Society for Pediatric and } \\
\text { Adolescent Diabetes) }\end{array}$ & 2011 & $\begin{array}{l}\text { BMI }>85 \text { th\% with other risk factors. } \\
\text { In Asian children, screen with low or } \\
\text { high birth weight with } 1 \text { risk factor, } \\
\text { regardless of BMI }\end{array}$ & $\begin{array}{l}\text { Immediate family history of T2DM, } \\
\text { early family history of CVD, or } \\
\text { Signs of insulin resistance (AN, } \\
\text { dyslipidemia, HBP, PCOS) }\end{array}$ \\
\hline \multicolumn{4}{|c|}{ Overweight/Obesity screening } \\
\hline USPSTF (Barton 2010) & 2010 & Screen at 6 year and older for obesity & \\
\hline $\begin{array}{l}\text { Expert Committee } \\
\text { (Barlow 2007) }\end{array}$ & 2007 & $\begin{array}{l}\text { Every well child visit: height and } \\
\text { weight, calculate and plot BMI }\end{array}$ & \\
\hline
\end{tabular}

${ }^{a}$ The ISPAD guidelines are also sensitive to country resources, so that screening decisions will likely be tied directly to the health-care resources with a country

${ }^{b}$ Native American, African-American, Latino, Asian American, Pacific Islander

et al. 2013), and although less is currently known about how the disease develops in children and adolescents, this is an area of active investigation.

\subsection{Diabetes Prevention}

A number of lifestyle interventions to prevent T2DM in youth at high risk have been evaluated in randomized trials. The Yale Bright Bodies Healthy Lifestyle program is an intensive 6-month behavioral intervention for obese youth and their families that has been evaluated in multiple randomized controlled trials (Savoye et al. 2007, 2011, 2014). Among 174 ethnically diverse children and adolescents aged 8-16 years -69 assigned to the control condition - the youth in the intervention group showed reductions in adiposity at 6 months that were maintained at 1 year as well as reductions in fasting insulin levels, which were seen at 6 months and also maintained for 1 year (Savoye et al. 2007). These youth were also assessed 24 months after the start of the trial and the favorable changes in body composition and insulin sensitivity seen at 6 and 12 months were sustained at similar levels at 24 months (Savoye et al. 2011). A subsequent trial among $10-16$-year-olds with prediabetes $(n=38$ receiving the Bright Bodies intervention and $n=37$ standard clinical care) also demonstrated improvements in glucose metabolism and insulin sensitivity as well as reductions in adiposity and improved fitness (Savoye et al. 2014). Such results are encouraging, and although the intervention is intensive, it uses a standardized curriculum and is likely to be cost-effective long term (Savoye et al. 2014).

The HEALTHY Study was a national 3-year middle-school intervention program designed to reduce risk factors for type 2 diabetes. It used a randomized trial designed to determine whether 
changes to the school environment of middleschool students over a 3-year period could impact their risk for T2DM (Foster et al. 2010; Hirst et al. 2009). Prevention of T2DM in youth involves encouraging changes in eating and activity behaviors that should also reduce risk for obesity. Although many large and well-conducted randomized trials of school-based interventions to prevent obesity have had limited impact on obesity prevalence (Luepker et al. 1996; Caballero et al. 2003; Brown and Summerbell 2009), such interventions may improve glucose homeostasis and other risk factors for T2DM (Trevino et al. 2004; Rosenbaum et al. 2007). The Healthy Study was a group randomized trial conducted in 42 middle schools (21 intervention, 21 control) in 7 areas of the USA between fall 2006 and spring 2009 (Hirst et al. 2009). Students were in 6th grade when enrolled and in 8th grade when outcomes were assessed. The interventions in the Healthy Study included changes to the school environment with regard to nutrition (Gillis et al. 2009), physical activity (McMurray et al. 2009), and health messaging (Venditti et al. 2009). The primary outcome was prevalence of BMI $\geq 85$ th percentile (overweight and obesity), and at baseline about $50 \%$ of students in intervention and control schools were overweight or obese (Kaufman et al. 2009). Over the course of the study, this prevalence decreased in intervention schools to $45.8 \%$ and in control schools to $45.2 \%$, and thus there was not an effect of the intervention on the prevalence of overweight and obesity (Foster et al. 2010). However, the intervention did have a modest and statistically impact on the secondary outcomes of obesity, mean BMI $\mathrm{z}$-score, high waist circumference, and fasting insulin levels (Foster et al. 2010). These results suggest that changes to the school environment regarding nutrition, physical activity, and health messaging may reduce the risk of childhood onset of T2DM (Foster et al. 2010)

Some evidence suggests that interventions targeting physical fitness may be as effective in reducing risk for T2DM in youth as multicomponent interventions. Among obese 7-11-year-old children, a program of 40 min of aerobic exercise 5 days per week for 4 months reduced adiposity and insulin levels, but these effects were not sustained in the absence of the program (Ferguson et al. 1999). A dose-response effect for the benefit of time spent in exercise on fitness and cardiometabolic measures of T2DM risk was demonstrated in a subsequent study of overweight and obese 7-11-year-olds randomized to a 10-15-week program of 20 or 40 min per school day of aerobic activity or to a control group (Davis et al. 2012). Similar findings were noted in a pilot randomized study in which physical activity was added to a family-based weight control treatment. The exercise group had lower visceral abdominal fat posttreatment, a result that may be key in future work to reduce diabetes risk (Saelens et al. 2011). In a YMCA-based program targeted to prevent the development of T2DM in high-risk inner-city African-American children (TAT: Taking Action Together), initial results were encouraging with improvement in glucoregulation in boys (but not girls) and a decrease in BMI z-scores in the treatment group (Ritchie et al. 2010; Raman et al. 2010).

\subsection{Obesity Prevention}

Because of the strong association between obesity and T2DM, much of the literature that discusses prevention of T2DM focuses on weight reduction or healthy weight maintenance throughout childhood. In a systematic review of the effectiveness of weight management interventions in children, the US Preventative Services Task Force (USPSTF) results support at least in the short term benefits of comprehensive medium-to-high intensity behavioral interventions in children 6 years and older (Whitlock et al. 2010). The outcomes studied in the USPSTF review were limited to childhood weight and not the progression to T2DM (see Table 1).

Recent evidence points to the importance and benefit of intervening early in children's lives to reduce obesity (Knowlden and Sharma 2012), and a number of randomized controlled treatment trials in preschool-aged children have demonstrated success. An intensive 16-week multidisciplinary program for overweight or obese Dutch 
children aged 3-5 years and their parent was compared to a "usual-maintained care" control, and results showed reductions in BMI and waist circumference that were for 12 months (Bocca et al. 2012a). Among 33 obese preschool-aged (2-5 years) children in the Midwest USA, a pilot randomized trial compared two 6-month multidisciplinary treatment programs (one in which all sessions were held at a clinic and another program that alternated between clinic sessions and individual home-based visits by a pediatric psychology fellow); both interventions were consistent with Expert Committee (Barlow 2007) stage 3 recommendations and were compared to a control condition of pediatrician counseling as recommended by the Expert Committee as stage 1 treatment (Stark et al. 2014). Compared to pediatrician counseling, children in the intervention with home visits group had greater reductions in BMI z-score at 6 months (end of intervention) and at 12 months than did children in the clinic only intervention (Stark et al. 2014). These results suggest that parents of obese preschoolaged children may benefit from in-home guidance regarding implementation and maintenance of parenting behaviors related to weight reduction. In an observational study of children aged 6-16 years seeking treatment for obesity in Sweden, researchers evaluated whether age and severity of obesity impacted the likelihood of treatment success over a 3-year period (Danielsson et al. 2012). They found that younger children (6-9 years) were more likely to have clinically meaningful reductions in weight status than older children and adolescents, and that treatment success was rare for adolescents particularly if they were severely obese (Danielsson et al. 2012). The difficulties associated with treating obesity once it is established underscore the need to prevent excess weight gain in young children before they become obese.

It is well established that parents play a key role in obesity treatment efforts directed at youth (Kitzmann et al. 2010), and for obvious reasons parents are the main audience for obesity prevention efforts in early childhood (Skouteris et al. 2011, 2012; Hesketh and Campbell 2010).
Interventions directed at parents of infants have shown promise in reducing children's risk for obesity (Campbell et al. 2013; Wen et al. 2012), and parents of infants may be receptive to messaging aimed at increasing adoption of healthy eating and activity behaviors. Emerging evidence also suggests that interventions to promote positive parenting in general may help to reduce risk for childhood obesity (Harvey-Berino and Rourke 2003; Brotman et al. 2012). Maternal warmth and sensitivity are associated in prospective cohort studies with lower risk for obesity (Anderson et al. 2012, 2014). An explanatory mechanism may involve the impact of responsive parenting on the child's developing stress response system and regulatory pathways in the limbic areas of the brain (McEwen 2008; Schore 2005). In a national sample of preschool-aged children, the household routines of having family meals, ensuring that children get adequate sleep, and limiting time spent watching television were associated with lower prevalence of obesity (Anderson and Whitaker 2010). A randomized trial of a 6-month home-based intervention to promote these household routines in a sample of low-income families of 2-5-year-old children reduced children's BMI (Haines et al. 2013).

Recent evidence points to the importance of intervening early. In a randomized clinical trial targeting 3-5-year-old overweight or obese children, a multidisciplinary program reduced BMI, BMI Z-scores, waist circumference, and waist circumference $\mathrm{z}$-scores compared to a usual treatment control group. The treatment results were still present 12 months after the start of the intervention (Bocca et al. 2012b). A 6-month intensive home-based behavioral intervention program aimed at obese preschoolers (ages 2-5 years) has also shown promise in reducing BMI z-scores, both during the treatment period and at 12 months follow-up (Saelens et al. 2011). In an observational study of obese children ages 6-16 years, all were exposed to a behavioral treatment; changes in BMIs across a 3-year treatment window showed that younger aged children (6-9 compared with 14-16 years) were more successful in improving outcomes (Danielsson et al. 2012). 


\subsection{Screening Guidelines}

Given what we know about factors associated with diabetes, screening for T2DM in children and adolescents is linked to weight status of the child, age of the child, and pubertal status. Several groups have published guidelines for T2DM screening in children. These guidelines are summarized in Table 1.

\subsubsection{Growth in Childhood}

Birth weight and growth trajectories have both been recognized as factors that are associated with the life course risk of T2DM. Given this, it seems key that individuals from the start understand their risk and that primary-care providers collect these data for all children. Surprisingly few guidelines currently recommend including birth weight as a component of a child's risk assessment for T2DM. An exception to this is the ISPAD screening guidelines that include birth size in their guidelines for Asian children. No recommendations were found that considered the actual growth of the child with respect to possible high-risk trajectories. Including birth size and growth as screeners for high-risk children has yet to be fully examined. A better understanding of the growth trajectory may be useful in identifying high-risk children earlier, but further work is needed in this area.

\subsection{Summary}

Childhood is the period where health behaviors are formed. While there is evidence that these behaviors are influenced by experience in the prior developmental periods, there is also evidence that significant change is still possible, especially in children under 5 years. Increasing evidence from both observational and intervention studies suggests that behavioral change is possible early on, but by middle childhood it becomes increasingly more difficult to affect real behavior change. These findings are pushing the research community to design studies that include young children, and the evidence is accumulating that interventions at the youngest ages achieve the best outcomes. During this period the child's world widens as he/she transitions into preschool and kindergarten, raising further the need to widen the focus of intervention beyond the family.

\section{Adolescence}

\subsection{Transition into Adolescence}

Puberty is an important phase in the life course that needs to be considered in studying the risks for T2DM. During puberty there is a known physiological insulin resistance and hyperinsulinemia that is thought to facilitate pubertal weight gain and growth (Burt Solorzano and McCartney 2010). The timing of the start of this insulin resistance has been reported to begin in mid-childhood, some years before puberty (Jeffery et al. 2012). Understanding this insulin resistance as it relates to the pubertal process is of high importance, as the rates of childhood diabetes continue to rise. Obesity exaggerates this pubertal insulin resistance, especially in girls, and may partially explain advanced maturation in obese females (Burt Solorzano and McCartney 2010).

\subsection{Diagnosis of T2DM}

The rising prevalence of both type 1 and type 2 among children and adolescents, in conjunction with increasing obesity throughout the population, has complicated the diagnosis of diabetes type. Past reliance on phenotype to distinguish and diagnose type of diabetes is not reliable (Amed et al. 2010a; Rosenbloom et al. 2008). In obese adolescents who present with new-onset diabetes, measurement of pancreatic autoantibodies is recommended as necessary to differentiate the type of diabetes (Zeitler 2010).

\subsection{Treatment}

Overall, there are few published evidence-based treatment studies for pediatric T2DM. The ADA and the ISPAD have published treatment 
recommendations, but these are primarily consensus based and built on current guidelines for adult T2DM (Amed et al. 2010a; Herbst et al. 2014). There are a handful of studies that have either been conducted or are ongoing specifically to address pediatric T2DM, studies which address both questions of prevention and treatment.

Treatment for T2DM has been addressed in a large multicenter randomized clinical trial, the Treatment Options for T2DM in Adolescents and Youth (known as the TODAY Study) (Copeland et al. 2011). Subjects were between the ages of 10 and 17, diagnosed with T2DM for less than 2 years, and had a BMI percentile at or above the 85th percentile for age and sex. Subjects were randomized into one of 3 comparison groups: metformin monotherapy, metformin plus rosiglitazone, or metformin plus an intensive family lifestyle program. Rates of failure (defined as poor glycemic control) were $52 \%$ in metformin alone, $39 \%$ in metformin plus rosiglitazone, and $47 \%$ in metformin plus the lifestyle program. Greatest weight loss was seen in the metformin plus the lifestyle program (Zeitler et al. 2012). These results highlight the difficulty that the majority of adolescents have in maintaining good glycemic control and suggest that many will require insulin within a few years of diagnosis. Ongoing research is needed to determine optimal management strategies in adolescents with T2DM.

The goal of therapy is to achieve euglycemia. The blood glucose levels should be monitored based on individual needs. Self- monitored blood glucose testing may be done at premeal times, or limited to before breakfast and before dinner only. Postprandial blood glucose levels, obtained $2 \mathrm{~h}$ after dinner, also offer helpful data for dose titration. The hemoglobin A1c is monitored at the time of clinic follow-up every 3 months. This reflects the average blood glucose over the past 3 -month period. The aim of treatment is to achieve a hemoglobin A1c of less than $6.5 \%$ and the target blood glucose range $=70-120 \mathrm{mg} / \mathrm{dl}$.

The first intervention for treatment of T2DM remains healthy lifestyle modifications including dietary modifications (including decreasing caloric intake) and increasing physical activity and exercise regimens to achieve weight stabilization and ultimately weight loss. Data from a recent study suggests that regular exercise was associated with lowering of the hemoglobin A1c (Herbst et al. 2014). Initiating changes in portion control as well as food choices and implementing modest amounts of exercise often prove difficult. Often adolescents have long-standing overweight and obesity concerns. Lifestyle changes tend to be more successful if initiated by the whole family instead of the particular individual being targeted.

If the diagnostic parameters are consistent with T2DM, pharmacologic treatment will need to be initiated. The particular therapeutic regimen initiated is determined by the initial presentation of T2 DM. If the adolescent presents in diabetic ketoacidosis, insulin therapy is instituted, initially intravenously, with subsequent transition to subcutaneous insulin therapy after the resolution of the acute diabetes ketoacidosis phase. Oral medication, specifically metformin, is initiated as well once the ketosis has resolved. If the presentation of T2DM is less acute, with the diagnosis being made on routine office testing, and hemoglobin A1c is less than 9\%, medication therapy may be initiated first with metformin. In patients with symptomatology in between these 2 scenarios, where hemoglobin A1c is more than $9 \%$ in the presence of typical symptomatology, but no diabetes ketoacidosis, therapy may be initiated with metformin along with basal insulin (Zeitler et al. 2014). Other medications used for treatment of T2DM in adults are not approved for adolescents below 16 years of age.

Adherence to therapeutic interventions is key for achieving adequate diabetes control and is strongly emphasized. Modifications to regimen are based on hemoglobin A1c and review of blood glucose data. Adolescents who are on metformin therapy as well as basal insulin may need additional rapid acting insulin to cover their meals. Adolescents who were initiated on insulin and metformin, and achieve goal A1c, are feasible to gradually decrease the insulin dose, after they are on maximal metformin dosing. If adolescents are able to modify lifestyle factors as well 
as manage medication therapy adequately, it may be feasible to discontinue insulin altogether, while continuing on metformin therapy, albeit done very gradually with close monitoring.

\subsubsection{Bariatric Surgery}

Bariatric surgery for weight loss or uncontrolled T2DM is not commonly undertaken in the adolescent population. Results obtained in studies with adults that report weight loss and improvement in T2DM after bariatric surgery procedures (Courcoulas et al. 2014) has caused increased interest in its use in adolescents with morbid obesity. When bariatric surgery has been used as a treatment strategy for extreme obesity in adolescents, it has been found to be effective in improving or reversing abnormal glucose metabolism, but long-term outcome data in this age group is not yet available. This treatment option is limited to a very specific population because of potential complications (Brandt et al. 2010).

\subsection{Surveillance}

Comorbidities associated with T2DM should be investigated and treated as needed based on individual clinical presentation. The ADA and the ISPAD have published guidelines for comorbidity screening in youth diagnosed with T2DM. These guidelines are summarized in Table 2.

In a study examining adherence to ADA recommendations for lipid levels, blood pressure, hemoglobin A1c, microalbuminuria, and eye examinations, $95 \%$ of the participants reported having their blood pressure checked at all or most visits, $88 \%$ had lipid levels measured, $83 \%$ had kidney function tested, $68 \%$ underwent $\mathrm{HbA1c}$ testing, and $66 \%$ underwent an eye examination (Waitzfelder et al. 2011). Participants aged 18 years or older, particularly those with T2DM, tended to have fewer tests of all kinds performed. Age and family income emerged as important correlates of overall quality of care in multivariate models: older age and lower income were associated with not meeting the guidelines. Overall, while there was good compliance with the ADA-recommended guidelines, efforts to improve $\mathrm{HbA} 1 \mathrm{c}$ testing and eye examinations were needed, especially among older adolescents and young adults (Waitzfelder et al. 2011).

\subsection{Comorbidities}

The TODAY study has demonstrated that a significant portion of adolescents with T2DM develop comorbidities. Careful attention to these

Table 2 Summary of surveillance guidelines for comorbidities

\begin{tabular}{l|l|l}
\hline & Year & Recommendations \\
\hline $\begin{array}{l}\text { ADA (Amercian Diabetes } \\
\text { Association 2000) }\end{array}$ & 2012 & $\begin{array}{l}\text { Blood pressure measurement annually } \\
\text { Fasting lipid profile } \\
\text { Microalbuminuria assessment } \\
\text { Dilated eye examination performed at the time of diagnosis } \\
\text { Evaluation of polycystic ovarian disease and other comorbidities such } \\
\text { as sleep apnea, hepatic steatosis, orthopedic complications, and } \\
\text { psychosocial concerns }\end{array}$ \\
\hline ISPAD (ISPAD 2011) & \multirow{2}{*}{$\begin{array}{l}\text { Blood pressure measured at least annually } \\
\text { Initial eye examination within 3 months of diagnosis and then annually } \\
\text { from 11 years on after 2 years of diabetes duration } \\
\text { Annual screening for microalbuminuria from age 11 and after 2 years } \\
\text { of diabetes duration } \\
\text { Fasting blood lipids after initial diagnosis and stabilization of diabetes } \\
\text { 12 years; if family history of hypercholesterolemia, early CVD, or } \\
\text { family history is unknown, screening should start at 2 years } \\
\text { Peripheral and autonomic neuropathy assessed by history and physical } \\
\text { exam from age 11 years with 2 years of diabetes duration }\end{array}$} \\
\hline
\end{tabular}


must be part of any management plan for these youths. Common comorbidities include hypertension and other metabolic conditions. Table 2 summarizes guidelines for monitoring the development of comorbidities in children/adolescents with T2DM.

\subsection{Care Transition into Adult Practice}

The emerging adult period (ages 18-30 years) is a high-risk time for youth with T2DM. These transitions from the pediatric to adult care setting often result in loss to follow-up at a time when the emergence of complications is occurring and the youth are engaging in high-risk health behaviors (Peters and Laffel 2011). In the majority of health-care institutions, there are no wellstructured, seamless processes in place to ensure smooth transitions of care for any chronic care condition. Furthermore, there is little evidencebased research to guide practice on the management of this care transition in youth with T2DM. In the absence of evidenced-based programs and because of concerns about this transition, many programs are in the process of designing and/or implementing transition of care initiatives (Lee 2013). In 2011, a consensus-based document outlining recommendations for transition from pediatric and to adult diabetes care systems was published. Part of this document specifically highlighted the need for research to determine the best strategies for transition to diabetic adult care to assure optimal outcomes for the youth (Peters and Laffel 2011).

\subsection{Summary}

Because T2DM is most likely diagnosed during or shortly after puberty, the emphasis in adolescence is focused on understanding the components of care for the disease, including the surveillance for and management of comorbidities. In adolescence the consequences of the child's early environments are becoming clear and the window for prevention has narrowed.

\section{Summary and Recommendations}

\subsection{Summary}

- Pediatric T2DM is a life course problem-this chapter demonstrates that no one factor and no one time period provides the explanation; prevention and treatment is not simple. To optimize childhood metabolic health, we must begin prior to conception and at every age seize the opportunities to shape the child's environment to enhance metabolic health development.

- Significant progress has been made in describing the growing pediatric T2DM epidemic and in identifying individual risk factors that contribute to its development. Work is ongoing to understand the underlying mechanisms of pediatric T2DM. This knowledge base will likely grow rapidly over the next decade.

- A major limitation of much of this work is that the studies tend to be singularly focused on exploring and understanding a particular risk, and are completed using a specific disciplinary approach. What is missing from most of this literature is the recognition that these risks exist within a dynamic developmental context with implications from micro- to macrosystems. The next generation of studies needs to consider how risks play out differently depending upon prior or current exposures and environments. What are the risk modifiers and mediators?

- Accounting for the influence of time-specific exposures during sensitive developmental periods in conjunction with exposures across time is limited in the current research, and must be addressed more thoroughly in future studies.

- Another major task facing pediatric T2DM researchers is to understand the developmental similarities and differences in T2DM between children and adults. When T2DM "threatens" or occurs in children/adolescents, the challenges of understanding and intervening are different from those in the adult population, both biologically and behaviorally. 
- Pediatric T2DM must be understood within the dynamic context of the child's overall health development. Research on the factors and developmental processes occurring early in life has shown how the emergence of T2DM children and adolescents is conditioned by prior experiences, exposures, and response patterns earlier in the life course.

- Translating the current knowledge into practice-relevant evidence is lagging and must be accelerated.

\subsection{Recommendations}

\subsubsection{Recommendation 1: To Continue to Elucidate Mechanisms that Contributes to Pediatric T2DM by Focusing the Research in Key Areas}

There are several parts to this recommendation including the identification of substantive research areas to guide further work, as well as recommendations about the process for doing the work. Life course health development research will require transdisciplinary teams of scientists that examine phenomenon across different levels (genetic, cellular, biological systems, families, neighborhoods, and large and complex macrosystems) at different developmental stage of the child. No one individual, and no one discipline, can achieve this knowledge by working in a disciplinary silo.

There are several areas that will require further investigation, and in particular we need to increase our understanding of factors that may mitigate the effects of adverse early-life programming. Childhood adversity, including the type of adversity (e.g., resource lack compared with family chaos), and chronic stress are noted as likely to be involved in the biological programming of several chronic health conditions including pediatric T2DM, but this is poorly accounted for in most of the current studies. Inclusion of poverty and family stress get at some of these factors, but better conceptual and empirical models are needed. Furthermore, the timing of the exposure for these risks is also not well documented, and their time-specific impacts are not well understood (i.e., is it poverty during pregnancy, during early childhood, or both?). On the positive side, there is a small but growing literature on the importance of parenting style, particularly nurturing behaviors, as possibly ways of mitigating the negative effects of various types of adverse environmental contexts.

Research priorities include:

- Understanding the health capital and health development capacity that mothers (and fathers) bring to conception and determine which of these factors are most important for child health development

- Determining how adult-recognized T2DM genetic susceptibility applies in pediatric T2DM

- Increased work to identify the epigenetic changes that occur in response to risk exposures (e.g., environmental toxins, stressors)

- Nutrition research, at every stage of childhood

- Understanding how health behaviors develop across time

But none of these are factors will provide a satisfactory explanation in isolation; each must be conditioned on prior and co-occurring factors. A life course health development perspective suggests that research must be embedded within the life stage of the child, taking into account the child's full developmental history, including the intrauterine period. Exploring contemporaneous factors, e.g., physical activity, and their association with T2DM should be done conditional on prior life course exposures, not simply on current factors; for example, knowing that the child was exposed to diabetes in utero and the birth size of the infant may be key markers for understanding differential effects of contemporaneous factors. Figure 1 integrates these ideas to display the life stages along the horizontal axis and prevention, screening, and treatment/surveillance along the $y$ axis. Embedded within this figure but not displayed because of the complexity is that at each point multiple factors from multiple levels are transacting simultaneously to bring about an outcome. 


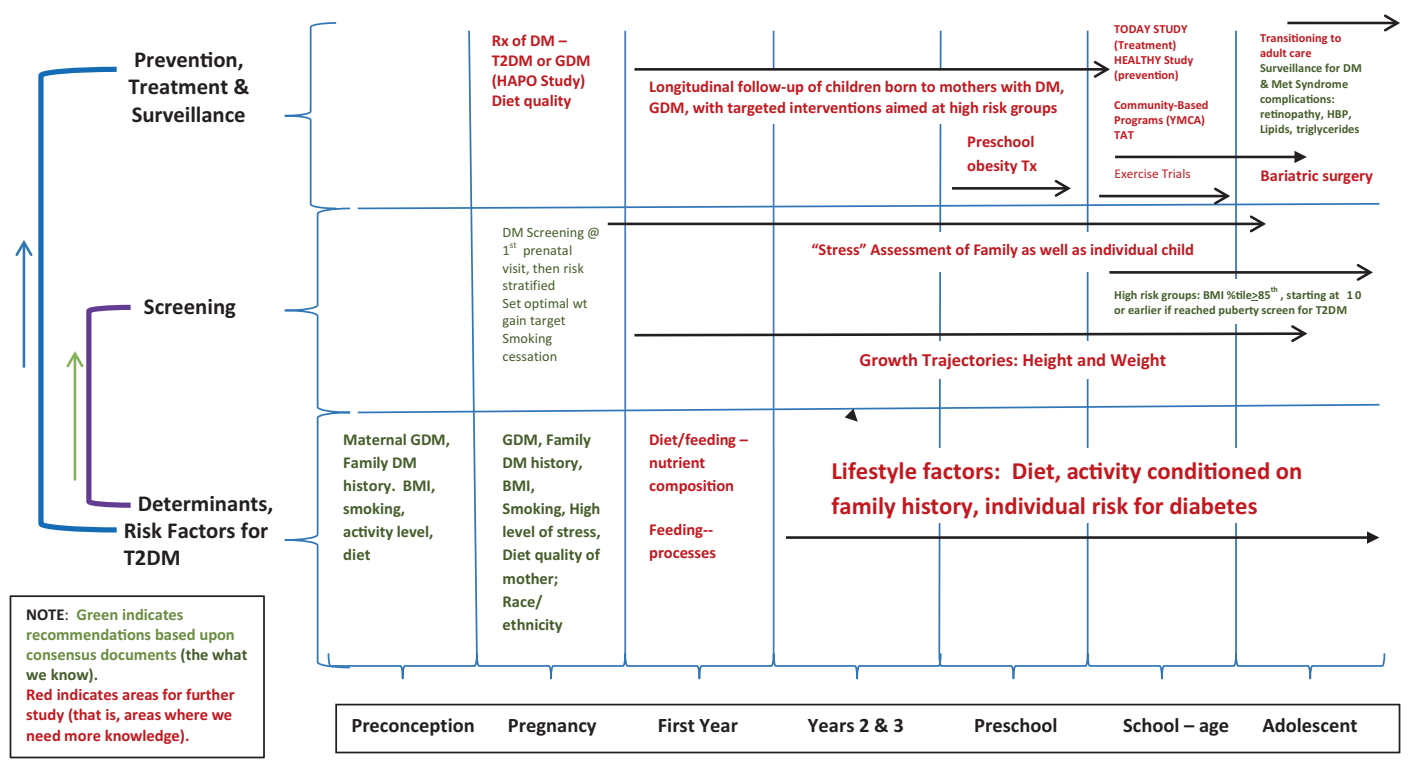

Fig. 1 A life course approach for understanding the risks, prevention and treatment of type 2 diabetes

\subsubsection{Recommendation 2: To Strengthen Data and Methods Used to Address Identified Research Priorities and Explore the Feasibility of an International Effort to Harmonize Ongoing Birth Cohorts for the Purpose of Developing a Better Understanding of the Timing, Dose, and Interaction of Factors that Contribute to Pediatric T2DM Worldwide}

Few data sets used to study the onset and impacts of T2DM include significant information on the broader context of the family, school, or neighborhood. In studies with good social data, biological data are often not included. A wider (micro to macro contexts) and longer (birth through adolescence) lens is needed to study T2DM. The need for longitudinal studies that can provide this lens is widely noted in the research literature, but because of the costs and subject burden, these long-term studies are difficult to carry out. However, there are a large number of longitudinal birth cohort studies ongoing worldwide that may have the potential for improving the understanding of pediatric T2DM. The recommendation here is to explore the feasibility of an international effort to harmonize ongoing birth cohorts to develop a better understanding of the timing, dose, and interactions of factors that contribute to T2DM worldwide. An added benefit of the development of such a data set is that it would provide the data to generate and test hypotheses, not just about T2DM but data directly relevant to the testing of the life course health development theoretical framework.

Table 3 presents an overview of international birth cohort studies. Of these studies, one dates to the 1950s, one to the 1960s, two during the 1970s, and another two in the 1980s. Twelve of the birth cohorts began data collection in the 1990s and 21 began data collection between 2000 and 2011. From this list, there are a handful of studies with data elements (birth data, multiple data collection points throughout childhood, including adolescent health and height and weight) pertinent to informing a life course picture of key pathways in this epidemic. Six birth cohorts were identified as having collected data beyond 1995 and included at least one data collection point in adolescence (defined as data 


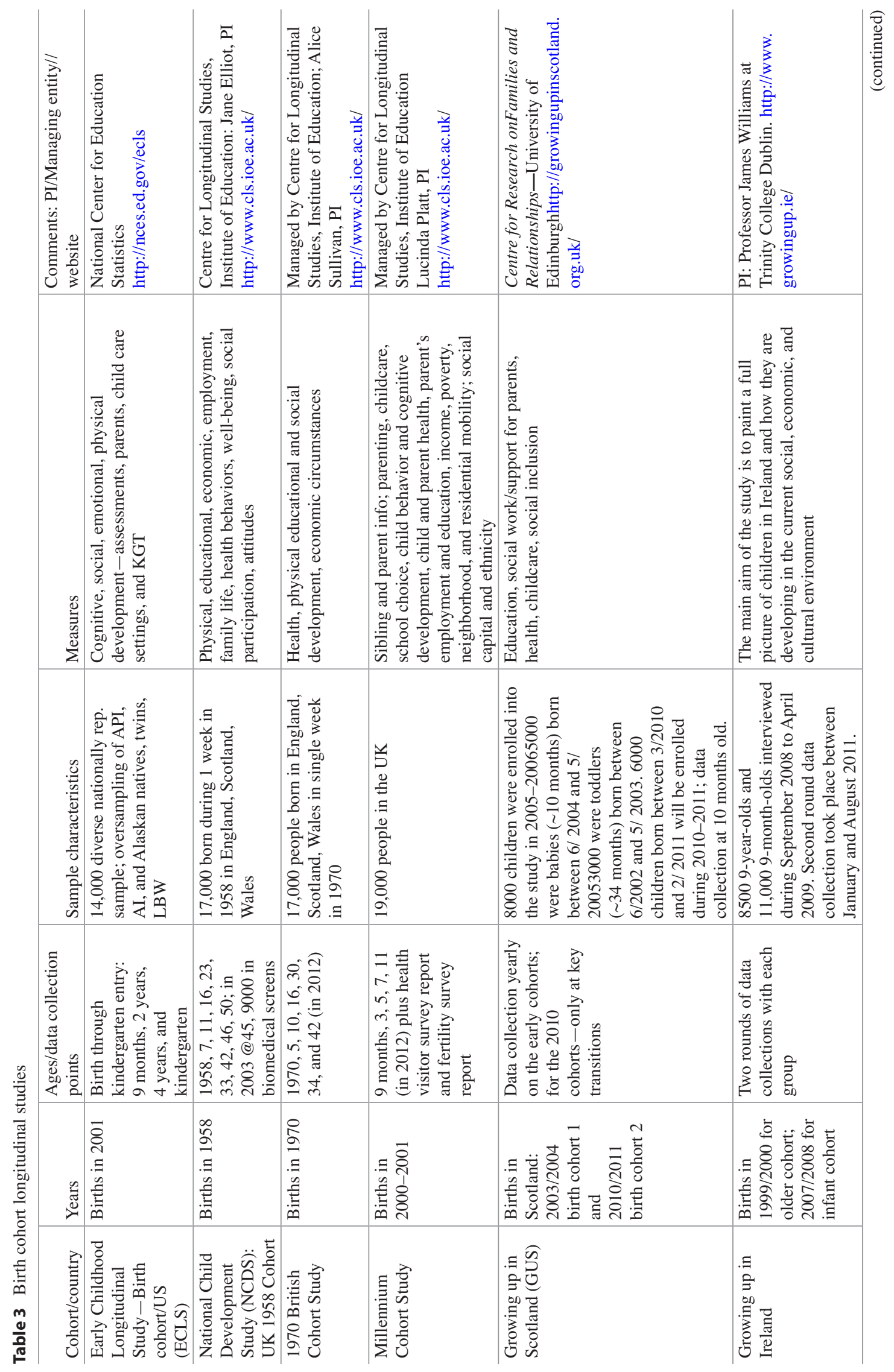




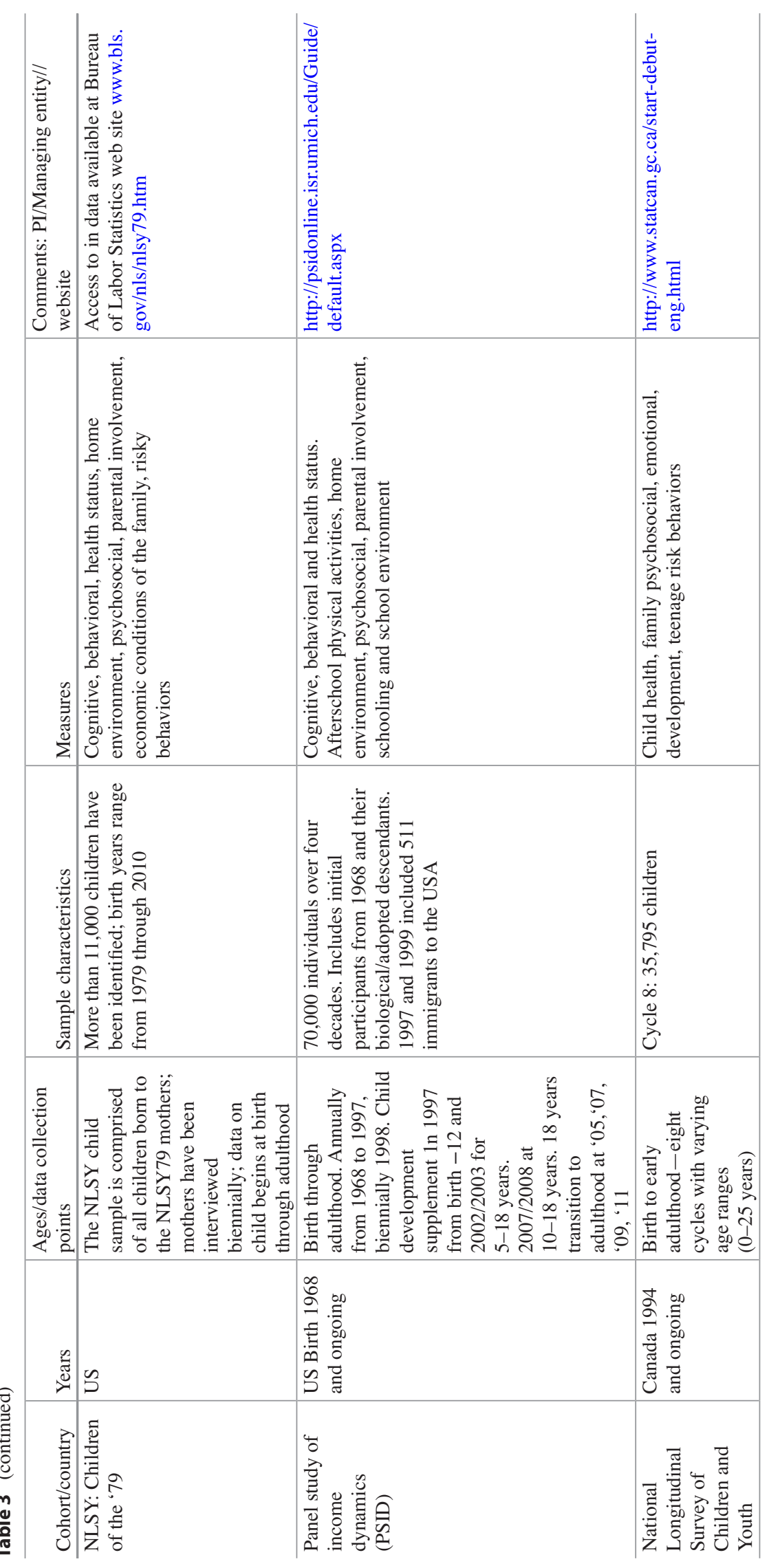




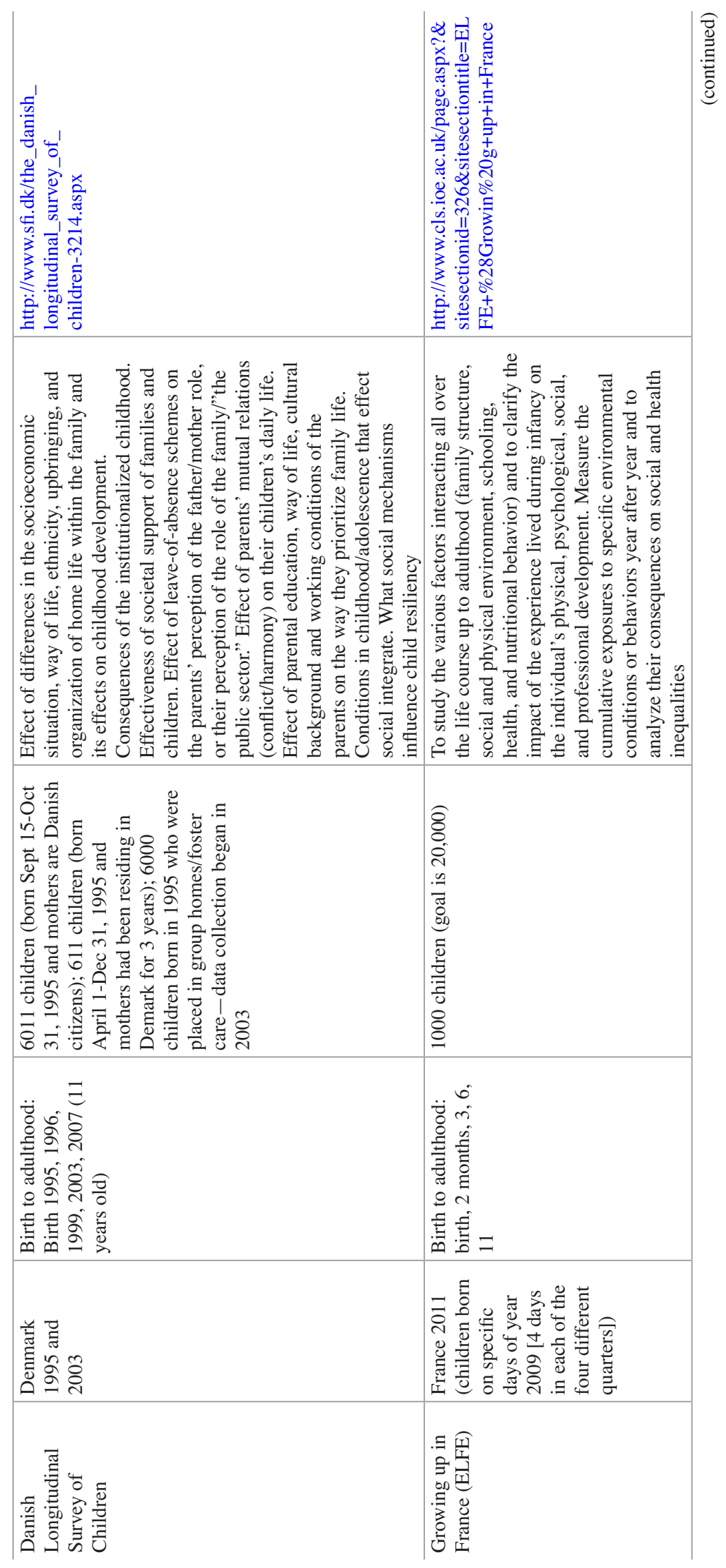




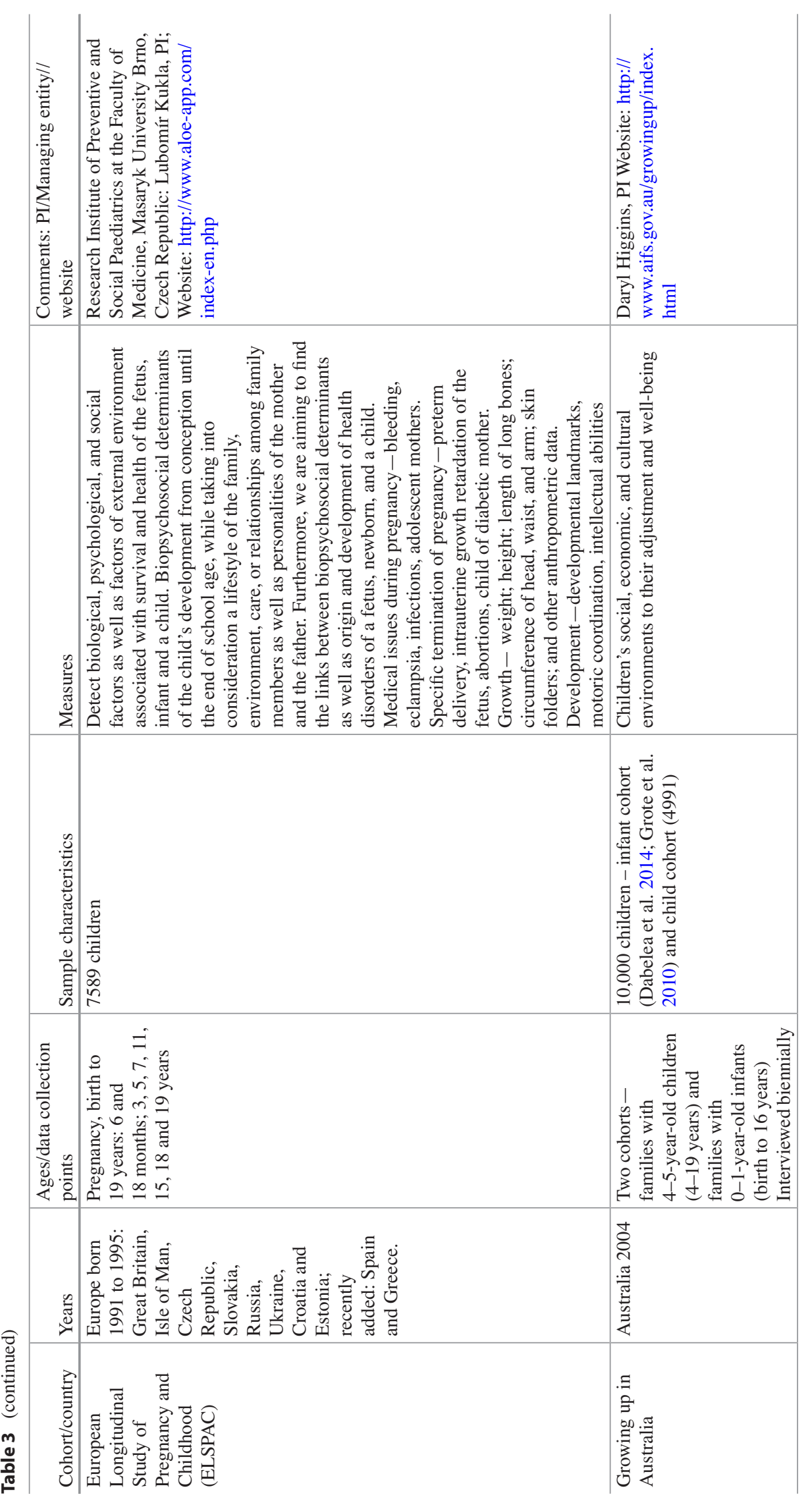




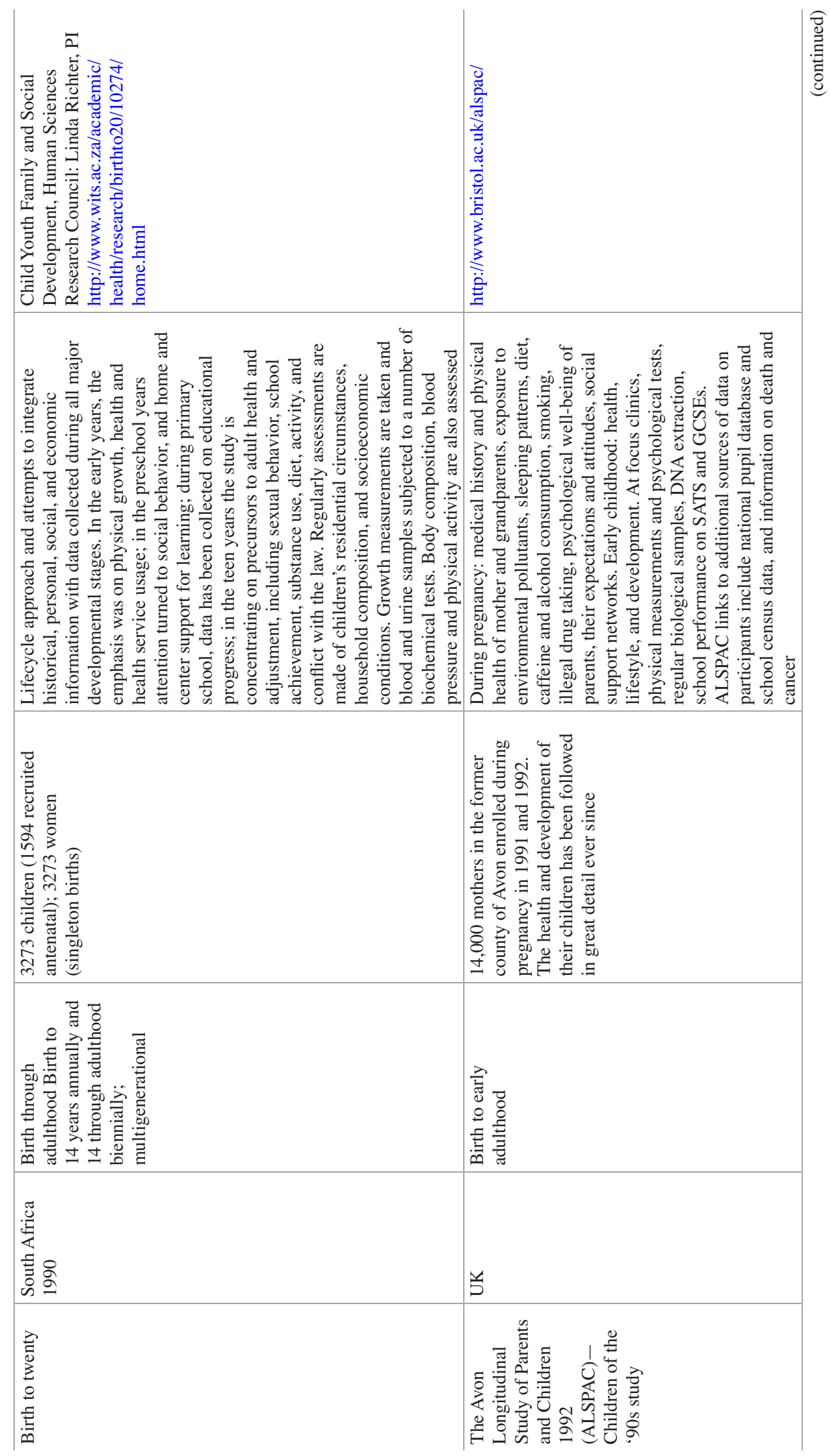




\begin{tabular}{|c|c|c|c|c|}
\hline 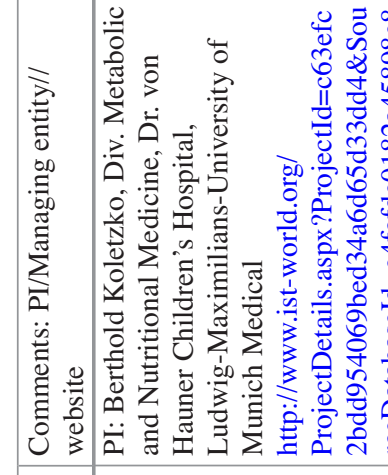 & 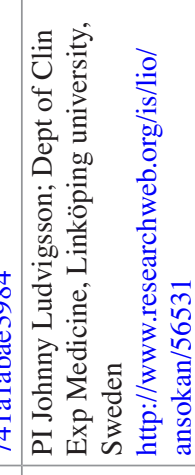 & 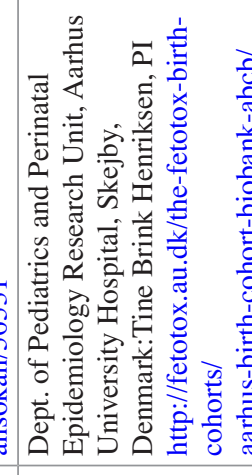 & 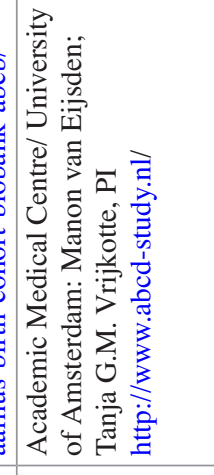 & 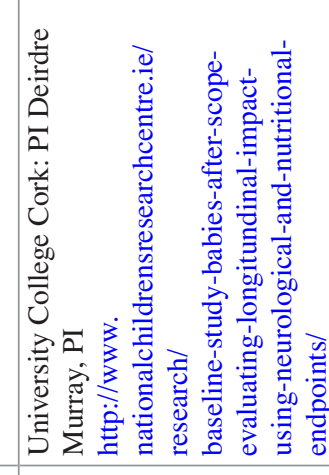 \\
\hline 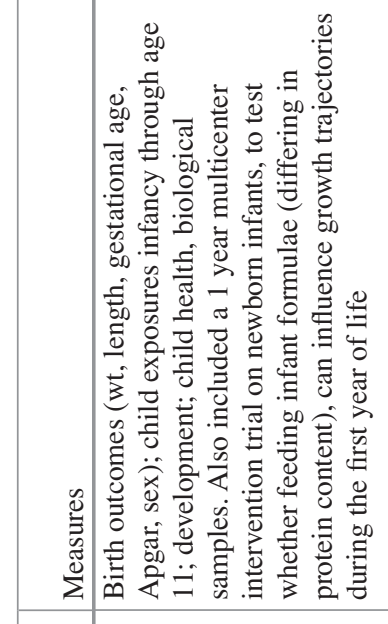 & 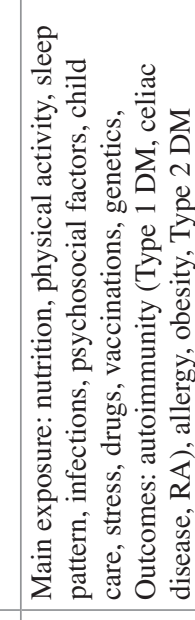 & 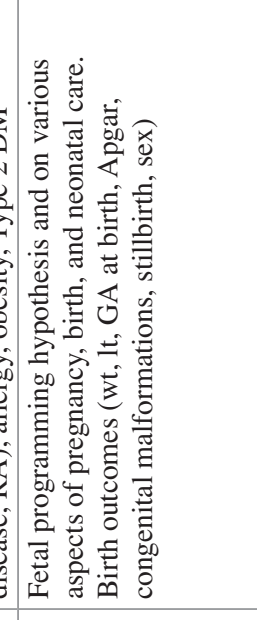 & 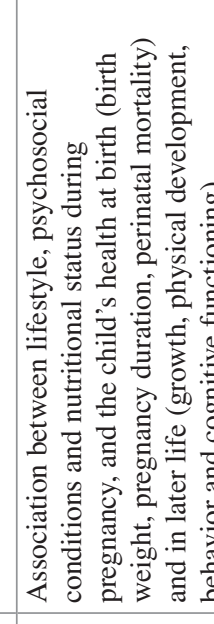 & 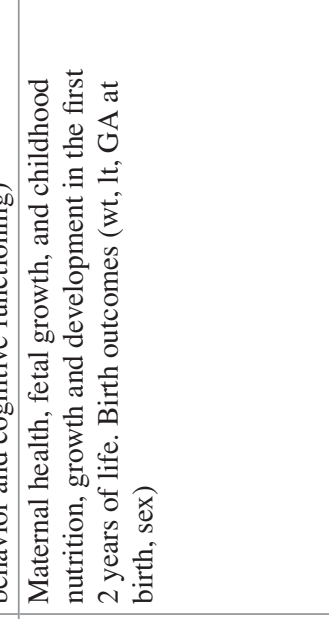 \\
\hline 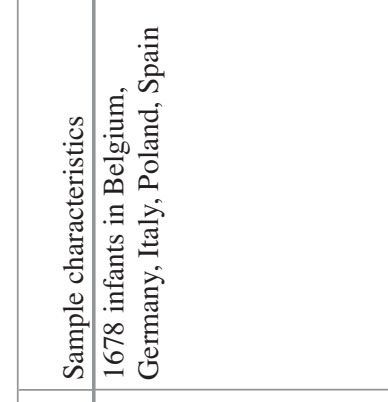 & 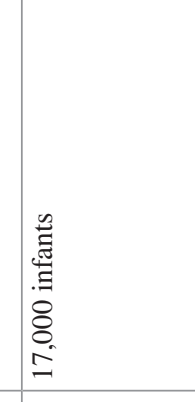 & 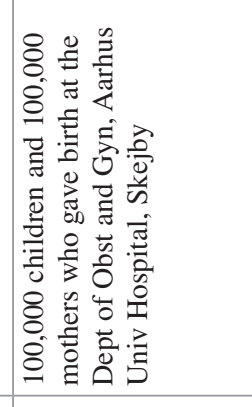 & 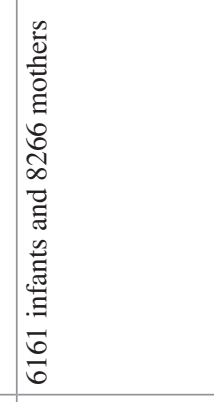 & 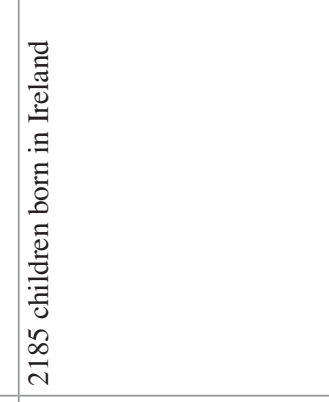 \\
\hline 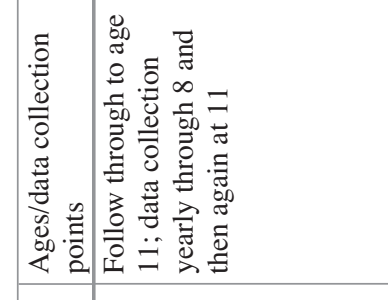 & 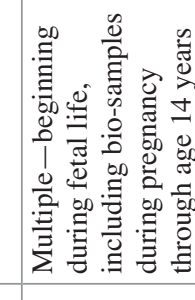 & 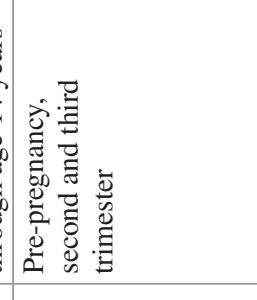 & 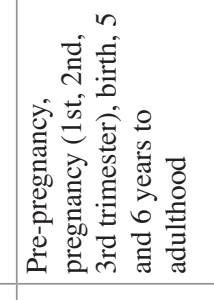 & 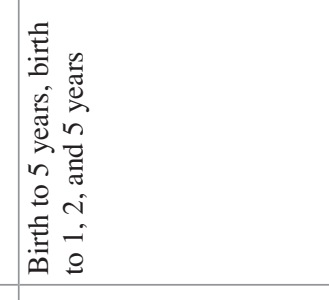 \\
\hline 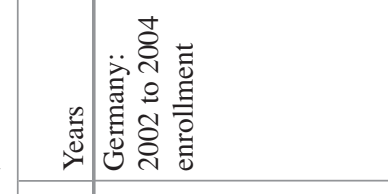 & 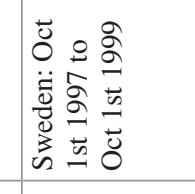 & 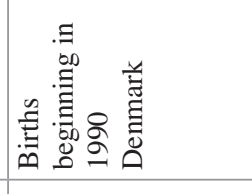 & 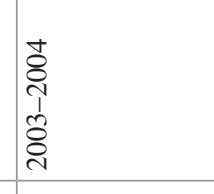 & 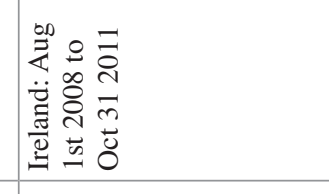 \\
\hline 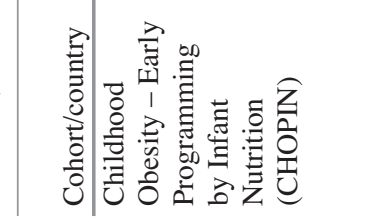 & 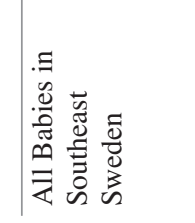 & 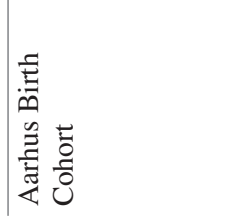 & 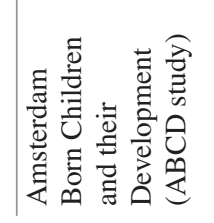 & 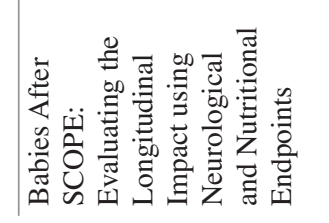 \\
\hline
\end{tabular}




\begin{tabular}{|c|c|c|c|c|}
\hline 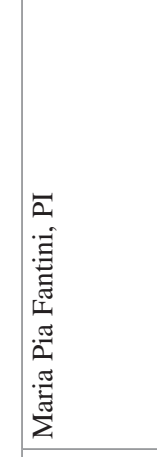 & 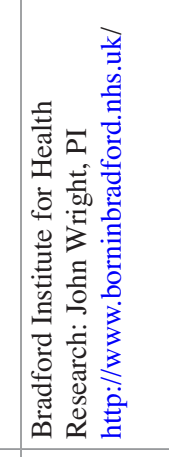 & 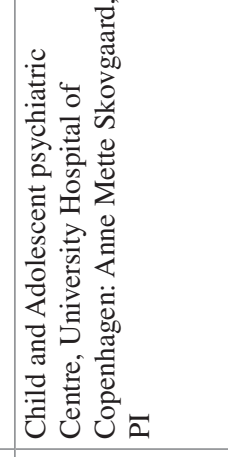 & 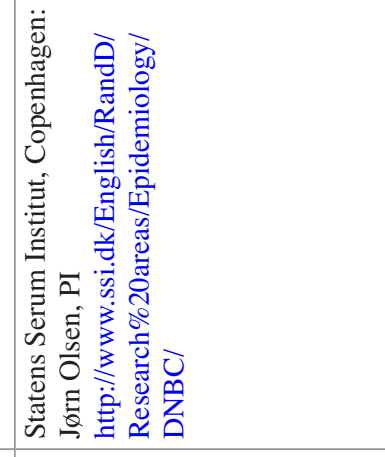 & 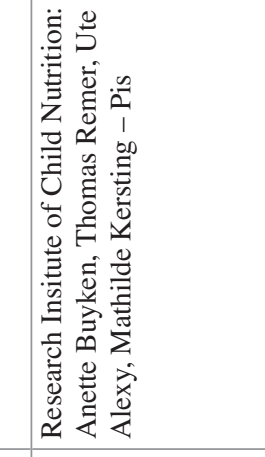 \\
\hline 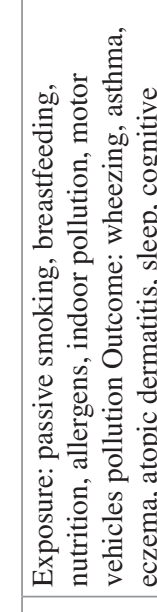 & 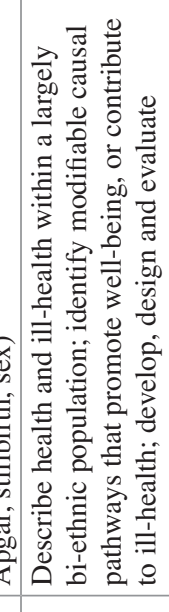 & 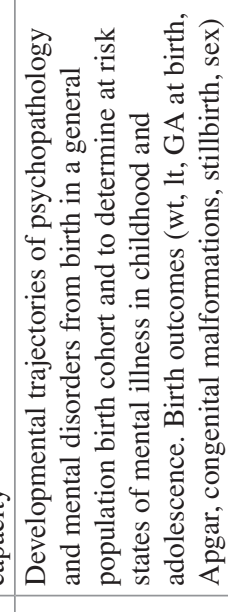 & 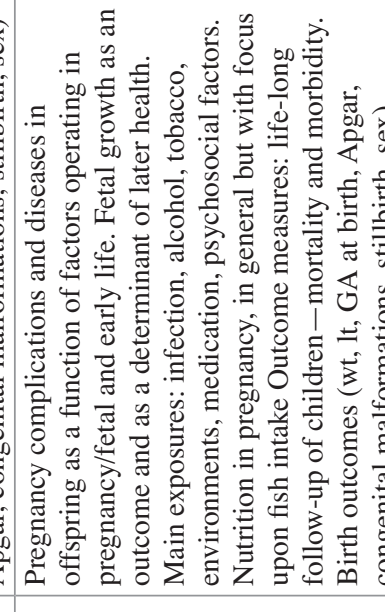 & 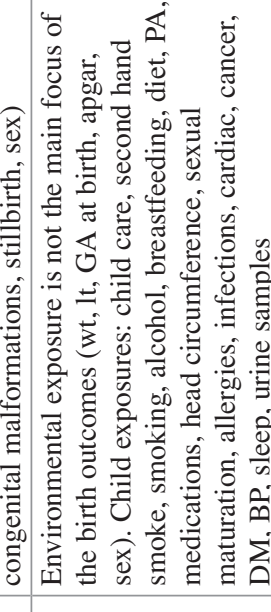 \\
\hline 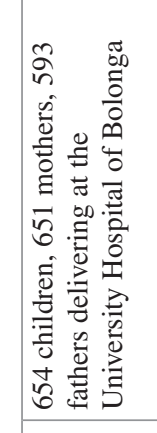 & 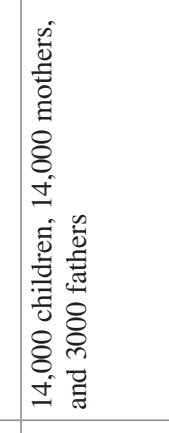 & 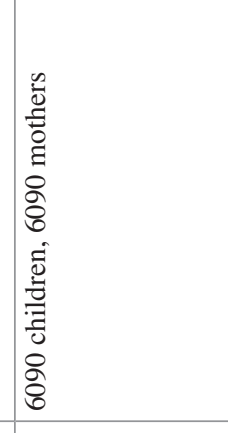 & 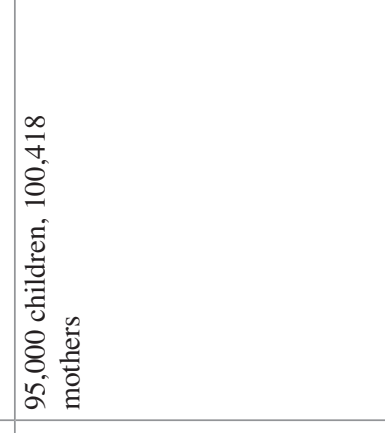 & 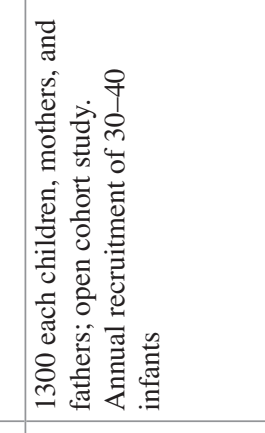 \\
\hline 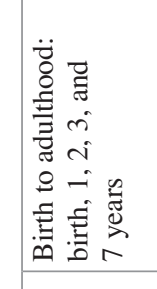 & 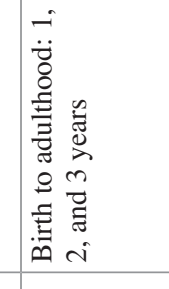 & 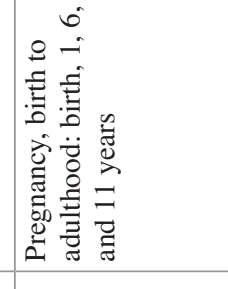 & 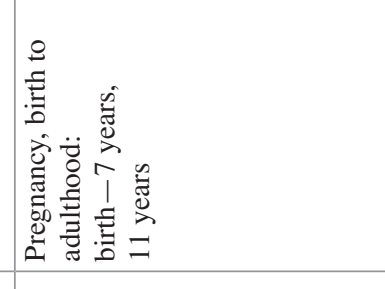 & 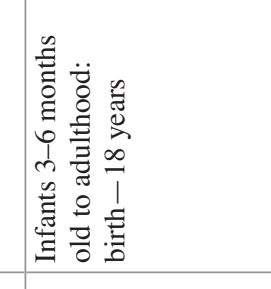 \\
\hline 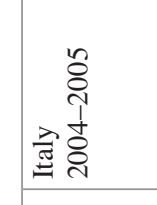 & 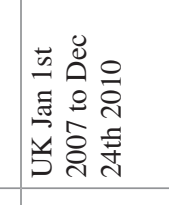 & 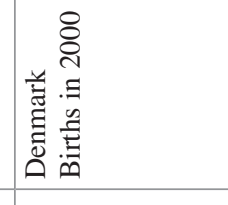 & 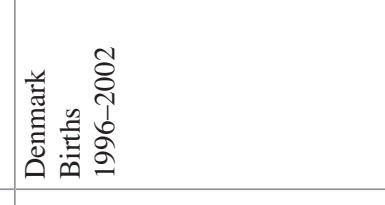 & 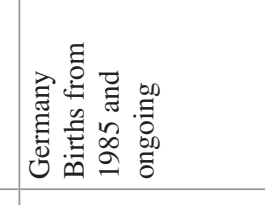 \\
\hline 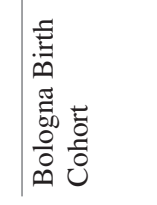 & 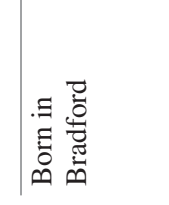 & 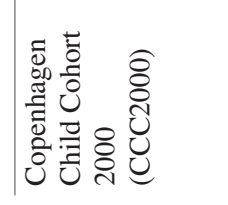 & 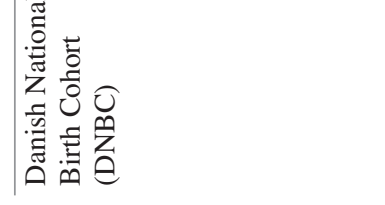 & 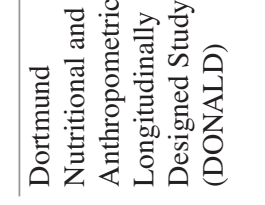 \\
\hline
\end{tabular}




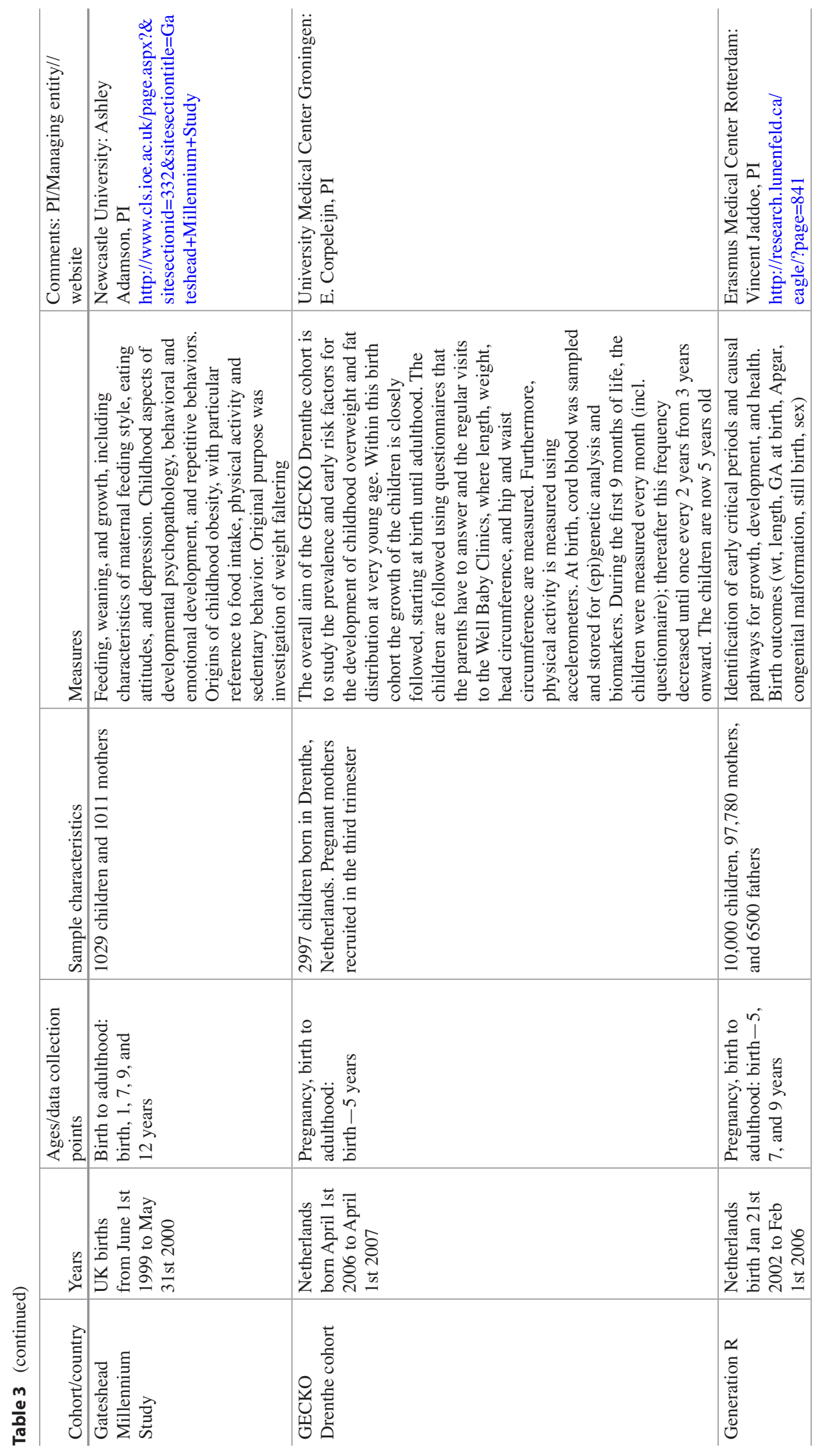




\begin{tabular}{|c|c|c|c|c|}
\hline 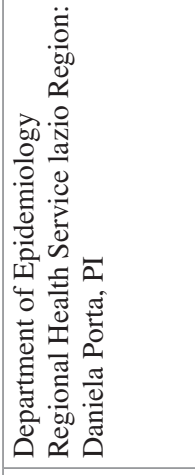 & 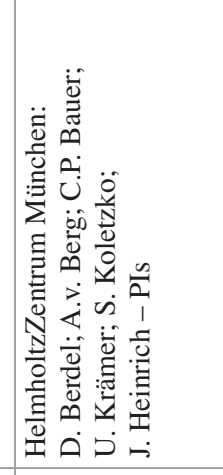 & 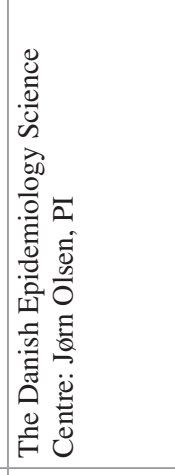 & 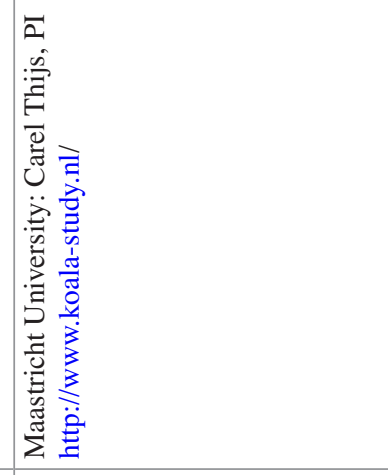 & 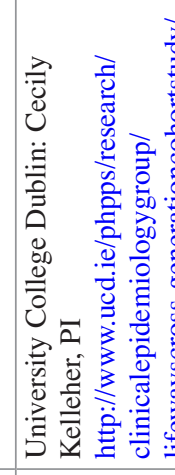 \\
\hline 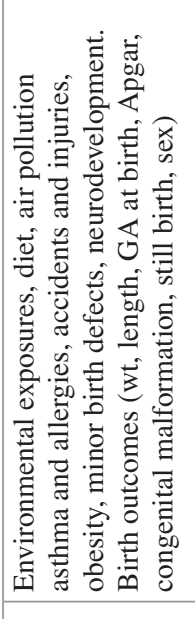 & 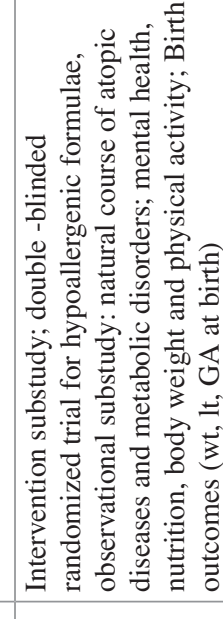 & 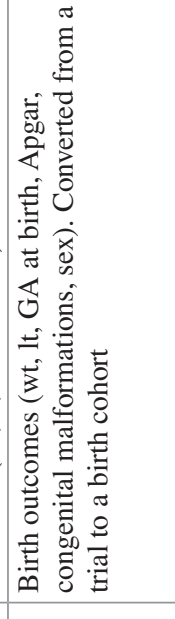 & 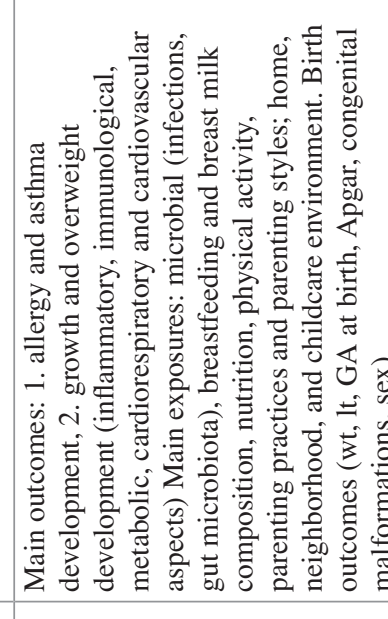 & 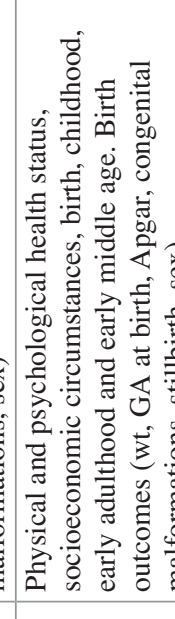 \\
\hline 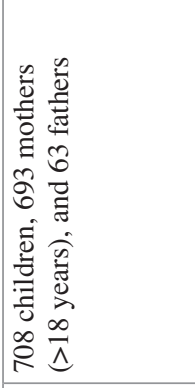 & 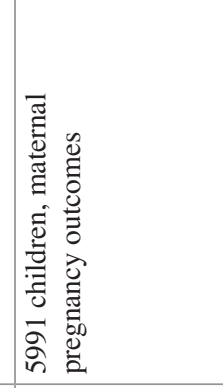 & 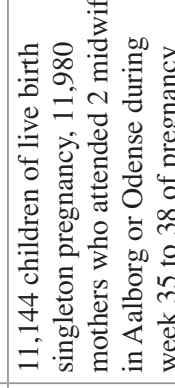 & 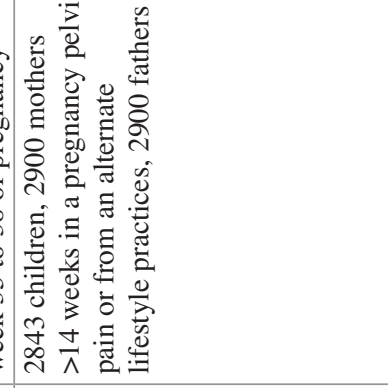 & 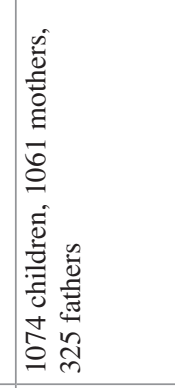 \\
\hline 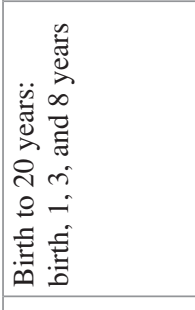 & 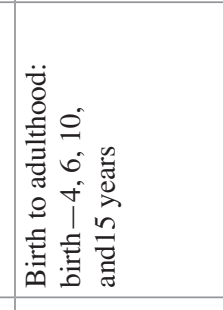 & 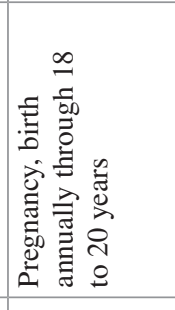 & 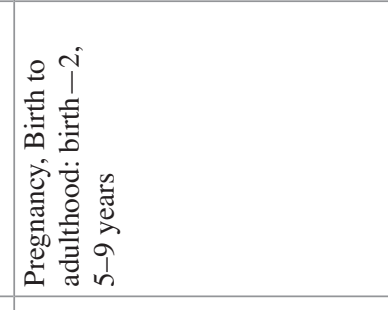 & 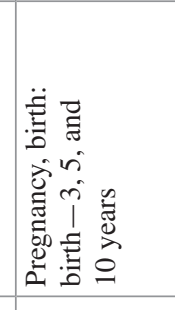 \\
\hline 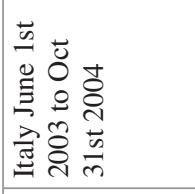 & 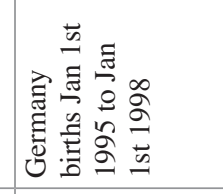 & 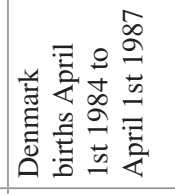 & 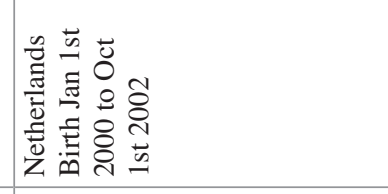 & 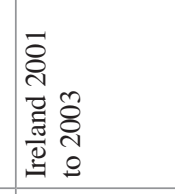 \\
\hline 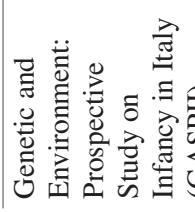 & 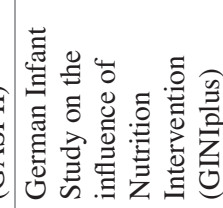 & 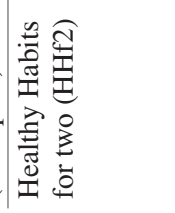 & 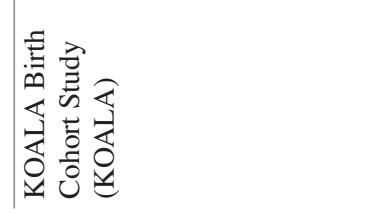 & 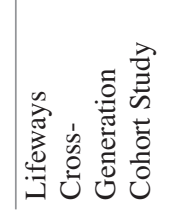 \\
\hline
\end{tabular}




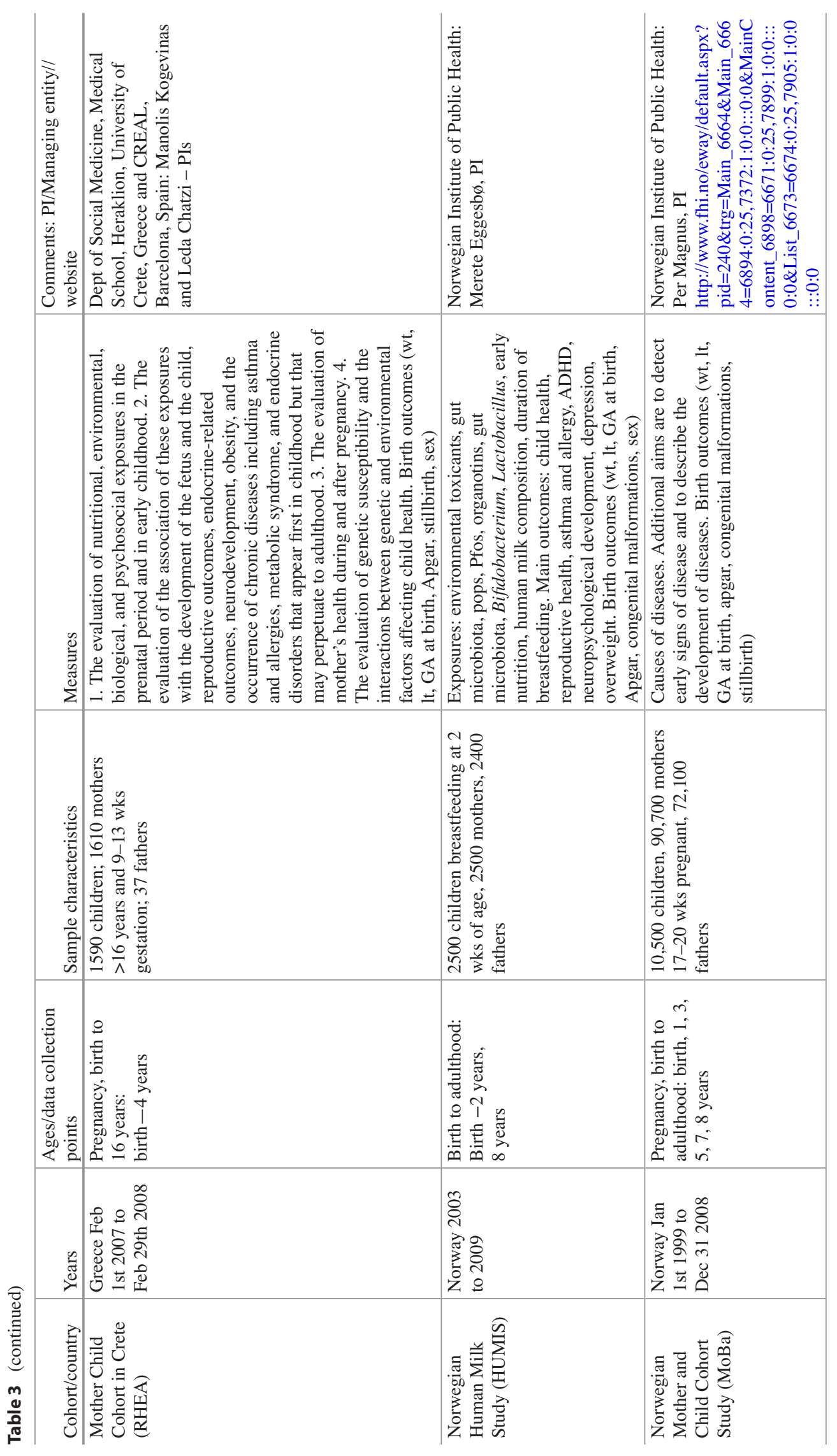




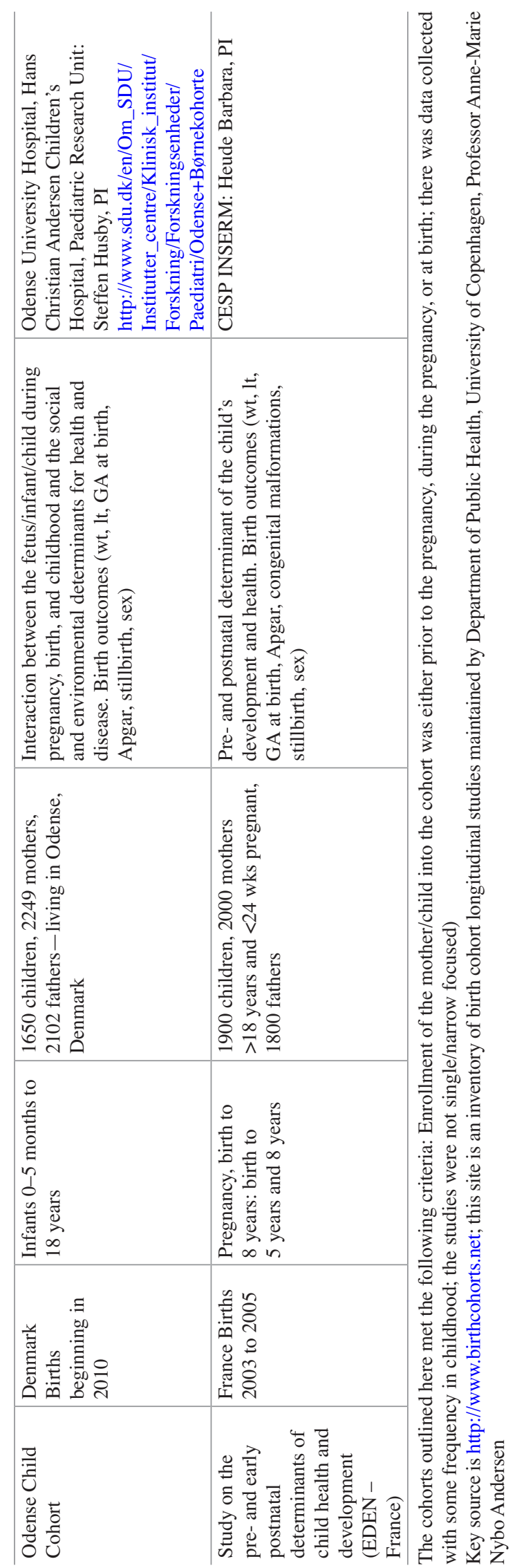


collection at 15 years or beyond). These cohorts also gathered data for childhood weight, height, health assessment, and various social parameters. The cohorts were the Canadian National Longitudinal Survey of Children and Youth (NLSCY, data collected at various age points from birth through age 25 over the course of 8 cycles), the European Longitudinal Study of Pregnancy and Childhood (ELSPAC, data collected at nine points from birth through 19 years and includes the countries of Great Britain, Isle of Man, Czech Republic, Slovakia, Russia, Ukraine, Croatia, Estonia, Spain and Greece), the Growing Up in Australia survey (data collected through two separate cohorts with one beginning at birth to 1 year and the second at 4/5 years with follow-up to age 19 years), the South Africa's Birth to 20 longitudinal study (data collected through two separate cohorts that followed children ages birth to 14 years and age 14 years through adulthood), the UK's Avon Longitudinal Study of Parents and Children (ALSPAC) (data collected on children born between 1990 and 1992 from birth through adulthood), and finally, the German Infant Study on the Influence of Nutrition Intervention (GINIplus), collected data on children born between 1995 and 1998 annually from birth through 4 years and then at 6, 10, and 15 years of age.

In addition to the data limitations currently facing the pediatric T2DM research community, there are also methodological/analytical challenges. To make progress in all of these research priorities, large amounts of data will be needed. These data will be diverse ranging from genetic and other biologicals to social structure factors. Management and analyses of such diverse data will require new methods and collaborations that will include basic scientists, mathematicians, data engineers, practitioners, and translational scientists. Researchers will need to employ big data analytics and a complex system perspective that can address multiple causes and outcomes. The challenges are significant, but the opportunities vast to make a real difference to the health development of all children

\subsubsection{Recommendation 3: To Translate the Growing Body of Knowledge into Evidenced- Based Prevention and Treatment Strategies}

There are clear needs for both prevention and treatment trials in children and adolescents. There is a dearth of evidence-based studies and guidelines available to pediatric practitioners and pediatric endocrinologist to address the multiple management issues faced when treating patients with T2DM. Areas of clear need include prevention strategies for children born at high risk. For example, low birth weight newborns, offspring of diabetic mothers, could be placed in programs to test interventions to modify risk. This is a very important area of pediatric and diabetes research with implications on health status and care for large number of children into adulthood and should be of high priority for funding agencies.

Prevention trials are needed that can identify strategies to reduce the risk for developing T2DM, and as recent work demonstrates, understanding the age at intervention is key. Prevention strategies may be gleaned from longitudinal data collected for other reasons. While not a prospective trial, the primary data elements could be supplemented either through new data collection efforts (e.g., during adolescence collecting insulin, glucose, etc.), or by combining the primary data with other administrative data-child electronic health records of heights and weights throughout childhood-or both. With home address information, child contexts could be tracked over time and neighborhoods accounted for in the analyses.

Finally, there is much work to be done to translate the knowledge into policy at every level. Pediatric practitioners need up-to-date guidelines to identify children at high risk for T2DM at young ages. Families must be given the information about the possible long-term consequences of decisions made in early life. Local, state, and national governments also need policies in place that enhance child health development throughout childhood. Only then will we be able to achieve the goal of optimal health development for every child. 


\section{References}

Aaltonen, J., Ojala, T., Laitinen, K., Poussa, T., Ozanne, S., \& Isolauri, E. (2011). Impact of maternal diet during pregnancy and breastfeeding on infant metabolic programming: A prospective randomized controlled study. European Journal of Clinical Nutrition, 65(1), $10-19$.

Agardh, E., Allebeck, P., Hallqvist, J., Moradi, T., \& Sidorchuk, A. (2011). Type 2 diabetes incidence and socio-economic position: A systematic review and meta-analysis. International Journal of Epidemiology, 40(3), 804-818.

Amed, S., Daneman, D., Mahmud, F. H., \& Hamilton, J. (2010a). Type 2 diabetes in children and adolescents. Expert Review of Cardiovascular Therapy, 8(3), 393-406.

Amed, S., Dean, H. J., Panagiotopoulos, C., Sellers, E. A., Hadjiyannakis, S., Laubscher, T. A., et al. (2010b). Type 2 diabetes, medication-induced diabetes, and monogenic diabetes in Canadian children: A prospective national surveillance study. Diabetes Care, 33(4), 786-791.

Amercian Diabetes Association. (2000). Type 2 diabetes in children and adolescents. Pediatrics, 105(3 Pt 1), 671-680.

American Academy of Pedicatrics. (2012). Breastfeeding and the use of human milk. Pediatrics, 129(3), e827-e841.

American Diabetes Association. (2010). Diagnosis and classification of diabetes mellitus. Diabetes Care, 33(Suppl 1), S62-S69.

Anderson, S. E., \& Whitaker, R. C. (2010). Household routines and obesity in US preschool-aged children. Pediatrics, 125(1), 420-428.

Anderson, S. E., Gooze, R. A., Lemeshow, S., \& Whitaker, R. C. (2012). Quality of early maternal-child relationship and risk of adolescent obesity. Pediatrics, 129(1), 132-140.

Anderson, S. E., Lemeshow, S., \& Whitaker, R. C. (2014). Maternal-infant relationship quality and risk of obesity at age 5.5 years in a national US cohort. $B M C$ Pediatrics, 14(1), 54.

Armitage, J. A., Khan, I. Y., Taylor, P. D., Nathanielsz, P. W., \& Poston, L. (2004). Developmental programming of the metabolic syndrome by maternal nutritional imbalance: How strong is the evidence from experimental models in mammals? The Journal of Physiology, 561(Pt 2), 355-377.

Armitage, J. A., Poston, L., Taylor, P., \& D. (2008). Developmental origins of obesity and the metabolic syndrome: The role of maternal obesity. Frontiers of Hormone Research, 36, 73-84.

Arslanian, S. A., Bacha, F., Saad, R., \& Gungor, N. (2005). Family history of type 2 diabetes is associated with decreased insulin sensitivity and an impaired balance between insulin sensitivity and insulin secretion in white youth. Diabetes Care, 28910, 115-119.

Barker, D. J., Hales, C. N., Fall, C. H., Osmond, C., Phipps, K., \& Clark, P. M. (1993). Type 2 (non-insulin- dependent) diabetes mellitus, hypertension and hyperlipidaemia (syndrome $\mathrm{X}$ ): Relation to reduced fetal growth. Diabetologia, 36(1), 62-67.

Barker, A., Sharp, S. J., Timpson, N. J., Bouatia-Naji, N., Warrington, N. M., Kanoni, S., et al. (2011). Association of genetic loci with glucose levels in childhood and adolescence: A meta-analysis of over 6,000 children. Diabetes, 60(6), 1805-1812.

Barlow, S. E. (2007). Expert committee recommendations regarding the prevention, assessment, and treatment of child and adolescent overweight and obesity: Summary report. Pediatrics, 120(Suppl 4), S164-S192.

Barouki, R., Gluckman, P. D., Grandjean, P., Hanson, M., \& Heindel, J. J. (2012). Developmental origins of non-communicable disease: Implications for research and public health. Environmental Health : A Global Access Science Source, 11, 42.

Barton, M. (2010). Screening for obesity in children and adolescents: US preventive services task Force recommendation statement. Pediatrics, 125(2), 361-367.

Battista, M. C., Hivert, M. F., Duval, K., \& Baillargeon, J. P. (2011). Intergenerational cycle of obesity and diabetes: How can we reduce the burdens of these conditions on the health of future generations? Experimental Diabetes Research, 2011, 596060. doi:10.1155/2011/596060.

Bell, J. F., \& Zimmerman, F. J. (2010). Shortened nighttime sleep duration in early life and subsequent childhood obesity. Archives of Pediatrics \& Adolescent Medicine, 164(9), 840-845.

Bell, R. A., Mayer-Davis, E. J., Beyer, J. W., D’Agostino, R. B., Jr., Lawrence, J. M., Linder, B., et al. (2009). Diabetes in non-Hispanic white youth: Prevalence, incidence, and clinical characteristics: The SEARCH for diabetes in youth study. Diabetes Care, 32(Suppl 2), S102-S111.

Berends, L. M., \& Ozanne, S. E. (2012). Early determinants of type-2 diabetes. Best Practice \& Research. Clinical Endocrinology \& Metabolism, 26(5), 569-580.

Bertin, E., Gangnerau, M. N., Bellon, G., Bailbe, D., Arbelot De Vacqueur, A., \& Portha, B. (2002). Development of beta-cell mass in fetuses of rats deprived of protein and/or energy in last trimester of pregnancy. American Journal of Physiology. Regulatory, Integrative and Comparative Physiology, 283(3), R623-R630.

Bocca, G., Corpeleijn, E., Stolk, R. P., \& Sauer, P. J. J. (2012a). Results of a multidisciplinary treatment program in 3-year-old to 5-year-old overweight or obese children: A randomized controlled clinical trial. Archives of Pediatrics \& Adolescent Medicine, 166(12), 1109-1115.

Bocca, G., Corpeleijn, E., Stolk, R. P., \& Sauer, P. J. (2012b). Results of a multidisciplinary treatment program in 3-year-old to 5-year-old overweight or obese children: A randomized controlled clinical trial. Archives of Pediatrics \& Adolescent Medicine, 166(12), 1109-1115.

Boekelheide, K., Blumberg, B., Chapin, R. E., Cote, I., Graziano, J. H., Janesick, A., et al. (2012). Predicting later-life outcomes of early-life expo- 
sures. Environmental Health Perspectives, 120(10), 1353-1361.

Boyle, J. P., Thompson, T. J., Gregg, E. W., Barker, L. E., \& Williamson, D. F. (2010). Projection of the year 2050 burden of diabetes in the US adult population: Dynamic modeling of incidence, mortality, and prediabetes prevalence. Population Health Metrics, 8, 29. doi:10.1186/1478-7954-8-29.

Brandt, M. L., Harmon, C. M., Helmrath, M. A., Inge, T. H., McKay, S. V., \& Michalsky, M. P. (2010). Morbid obesity in pediatric diabetes mellitus: Surgical options and outcomes. Nature reviews. Endocrinology, 6(11), 637-645.

Brotman, L. M., Dawson-McClure, S., Huang, K. Y., Theise, R., Kamboukos, D., Wang, J., et al. (2012). Early childhood family intervention and long-term obesity prevention among high-risk minority youth. Pediatrics, 129(3), e621-e628.

Brown, T., \& Summerbell, C. (2009). Systematic review of school-based interventions that focus on changing dietary intake and physical activity levels to prevent childhood obesity: An update to the obesity guidance produced by the National Institute for health and clinical excellence. Obesity Reviews, 10(1), 110-141.

Brunton, P. J. (2010). Resetting the dynamic range of hypothalamic-pituitary-adrenal axis stress responses through pregnancy. Journal of Neuroendocrinology, 22(11), 1198-1213.

Burns, S. F., Lee, S., Bacha, F., Tfayli, H., Hannon, T. S., \& Arslanian, S. A. (2014). Pre-diabetes in overweight youth and early atherogenic risk. Metabolism, 63(12), 1528-1235.

Burt Solorzano, C. M., \& McCartney, C. R. (2010). Obesity and the pubertal transition in girls and boys. Reproduction, 140(3), 399-410.

Caballero, B., Clay, T., Davis, S. M., Ethelbah, B., Rock, B. H., Lohman, T., et al. (2003). Pathways: A schoolbased, randomized controlled trial for the prevention of obesity in American Indian schoolchildren. American Journal of Clinical Nutrition, 78(5), 1030-1038.

Campbell, K. J., Lioret, S., McNaughton, S. A., Crawford, D. A., Salmon, J., Ball, K., et al. (2013). A parentfocused intervention to reduce infant obesity risk behaviors: A randomized trial. Pediatrics, 131(4), 652-660. doi:10.1542/peds.2012-2576.

Cenit, M. C., Matzaraki, V., Tigchelaar, E. F., \& Zhernakova, A. (2014). Rapidly expanding knowledge on the role of the gut microbiome in health and disease. Biochimica et Biophysica Acta, 1842(10), 1981-1992.

Christian, L. M. (2012). Physiological reactivity to psychological stress in human pregnancy: Current knowledge and future directions. Progress in Neurobiology, 99(2), 106-116. doi:10.1016/j.pneurobio.2012.07.003.

Copeland, K. C., Zeitler, P., Geffner, M., Guandalini, C., Higgins, J., Hirst, K., et al. (2011). Characteristics of adolescents and youth with recent-onset type 2 diabetes: The TODAY cohort at baseline. Journal of Clinical Endocrinology and Metabolism, 96(1), 159-167.

Courcoulas, A., Goodpaster, B., Eagleton, J., Belle, S., Kalarchian, M., Lang, W., et al. (2014). Surgical vs medical treatments for type 2 diabetes mellitus: A randomized clinical trial. JAMA Surgery, 7(149), $707-715$.

Crume, T. L., Ogden, L. G., Mayer-Davis, E. J., Hamman, R. F., Norris, J. M., Bischoff, K. J., et al. (2012). The impact of neonatal breast-feeding on growth trajectories of youth exposed and unexposed to diabetes in utero: The EPOCH study. International Journal of Obesity, 36(4), 529-534.

Dabelea, D., Bell, R. A., D'Agostino, R. B., Jr., Imperatore, G., Johansen, J. M., Linder, B., et al. (2007). Incidence of diabetes in youth in the United States. JAMA, 297(24), 2716-2724.

Dabelea, D., Dolan, L. M., D’Agostino, R., Jr., Hernandez, A. M., McAteer, J. B., Hammon, R. F., et al. (2011). Association testing of TCF7L2 polymorphisms with type 2 diabetes in multi-ethnic youth. Diabetologia, 54(3), 535-539.

Dabelea, D., Mayer-Davis, E. J., Saydah, S., Imperatore, G., Linder, B., et al. (2014). Prevalence of type 1 and type 2 diabetes among children and adolescents from 2001 to 2009. JAMA, 311(17), 1778-1786.

Danielsson, P., Kowalski, J., Ekblom, O., \& Marcus, C. (2012a). Response of severely obese children and adolescents to behavioral treatment. Archives of Pediatrics \& Adolescent Medicine, 166(12), 1103-1108.

Danielsson, P., Kowalski, J., Ekblom, O., \& Marcus, C. (2012b). Response of severely obese children and adolescents to behavioral treatment. Archives of Pediatrics \& Adolescent Medicine, 166(12), 1103-1108.

Davis, C. L., Pollock, N. K., Waller, J. L., Allison, J. D., Dennis, B. A., Bassali, R., et al. (2012). Exercise dose and diabetes risk in overweight and obese children: A randomized controlled trial. JAMA, 308(11), 1103-1112.

Demmer, R. T., Zuk, A. M., Rosenbaum, M., \& Desvarieux, M. (2013). Prevalence of diagnosed and undiagnosed type 2 diabetes mellitus among US adolescents: Results from the continuous NHANES, 1999-2010. American Journal of Epidemiology, 178(7), 1106-1113.

Devaraj, S., Hemarajata, P., \& Versalovic, J. (2013). The human gut microbiome and body metabolism: Implications for obesity and diabetes. Clinical Chemistry, 59(4), 617-628.

Dyer, J. S., \& Rosenfeld, C. R. (2011). Metabolic imprinting by prenatal, perinatal, and postnatal overnutrition: A review. Seminars in Reproductive Medicine, 29(3), 266-276.

van Eijsden, M., Vrijkotte, T. G., Gemke, R. J., \& van der Wal, M. F. (2011). Cohort profile: The Amsterdam born children and their development (ABCD) study. International Journal of Epidemiology, 40(5), 1176-1186.

Ekelund, U., Ong, K. K., Linne, Y., Neovius, M., Brage, S., Dunger, D. B., et al. (2007). Association of weight gain in infancy and early childhood with metabolic risk in young adults. The Journal of Clinical Endocrinology and Metabolism, 92(1), 98-103. 
Elder, D. A., Herbers, P. M., Weis, T., Standiford, D., Woo, J. G., \& D’Alessio, D. A. (2012). Beta-cell dysfunction in adolescents and adults with newly diagnosed type 2 diabetes mellitus. Journal of Pediatrics, 160(6), 904-910.

Eriksson, J. G. (2006). Early growth, and coronary heart disease and type 2 diabetes: Experiences from the Helsinki birth cohort studies. International Journal of Obesity, 30(Suppl 4), S18-S22.

Eriksson, J. G. (2011). Early growth and coronary heart disease and type 2 diabetes: Findings from the Helsinki birth cohort study (HBCS). The American Journal of Clinical Nutrition, 94(6 Supplement), 1799S-1802S.

Eriksson, J. G., Osmond, C., Kajantie, E., Forsen, T. J., \& Barker, D. J. (2006). Patterns of growth among children who later develop type 2 diabetes or its risk factors. Diabetologia, 49(12), 2853-2858.

Fabricius-Bjerre, S., Jensen, R. B., Faerch, K., Larsen, T., Molgaard, C., Michaelsen, K. F., et al. (2011). Impact of birth weight and early infant weight gain on insulin resistance and associated cardiovascular risk factors in adolescence. PloS One, 6(6), e20595. doi:10.1371/ journal.pone.0020595.

Ferguson, M. A., Gutin, B., Le, N. A., Karp, W., Litaker, M., Humphries, M., et al. (1999). Effects of exercise training and its cessation on components of the insulin resistance syndrome in obese children. International Journal of Obesity and Related Metabolic Disorders, 23(8), 889-895.

Fernandez-Twinn, D. S., Wayman, A., Ekizoglou, S., Martin, M. S., Hales, C. N., \& Ozanne, S. E. (2005). Maternal protein restriction leads to hyperinsulinemia and reduced insulin-signaling protein expression in 21-mo-old female rat offspring. American Journal of Physiology. Regulatory, Integrative and Comparative Physiology, 288(2), R368-R373.

Foster, G. D., Linder, B., Baranowski, T., Cooper, D. M., Goldberg, L., Harrell, J. S., et al. (2010). A schoolbased intervention for diabetes risk reduction. New England Journal of Medicine, 363(5), 443-453.

Gabbe, S. G., Landon, M. B., Warren-Boulton, E., \& Fradkin, J. (2012). Promoting health after gestational diabetes: A National Diabetes Education Program call to action. Obstetrics and Gynecology, 119(1), 171-176.

Gaffney, K. F., Kitsantas, P., \& Cheema, J. (2012). Clinical practice guidelines for feeding behaviors and weight-for-age at 12 months: A secondary analysis of the infant feeding practices study II. Worldviews on Evidence-Based Nursing, 9(4), 234-242.

Gaffney, K. F., Kitsantas, P., Brito, A., \& Swamidoss, C. S. (2014). Postpartum depression, infant feeding practices, and infant weight gain at six months of age. Journal of Pediatric Health Care, 28(1), 43-50.

Garofano, A., Czernichow, P., \& Breant, B. (1998). Betacell mass and proliferation following late fetal and early postnatal malnutrition in the rat. Diabetologia, 41(9), 1114-1120.

Gillis, B., Mobley, C., Stadler, D. D., Hartstein, J., Virus, A., Volpe, S. L., et al. (2009). Rationale, design and methods of the HEALTHY study nutrition interven- tion component. International Journal of Obesity, 33(Suppl 4), S29-S36.

Gillman, M. W., Oakey, H., Baghurst, P. A., Volkmer, R. E., Robinson, J. S., \& Crowther, C. A. (2010). Effect of treatment of gestational diabetes mellitus on obesity in the next generation. Diabetes Care, 33(5), 964-968.

Gluckman, P. D., Hanson, M. A., Cooper, C., \& Thornburg, K. L. (2008). Effect of in utero and early-life conditions on adult health and disease. New England Journal of Medicine, 359(1), 61-73.

Groop, L. C., \& Tuomi, T. (1997). Non-insulin-dependent diabetes mellitus-a collision between thrifty genes and an affluent society. Annals of Medicine, 29, 37-53.

Grote, V., Vik, T., von Kries, R., Luque, V., Socha, J., Verducci, E., et al. (2010). Maternal postnatal depression and child growth: A European cohort study. BMC Pediatrics, 10, 14. doi:10.1186/1471-2431-10-14.

Hadar, E., \& Hod, M. (2010). Establishing consensus criteria for the diagnosis of diabetes in pregnancy following the HAPO study. Annals of the New York Academy of Sciences, 1205, 88-93.

Haines, L., Wan, K. C., Lynn, R., Barrett, T. G., \& Shield, J. P. (2007). Rising incidence of type 2 diabetes in children in the U.K. Diabetes Care, 30(5), 1097-1101.

Haines, J., McDonald, J., O’Brien, A., Sherry, B., Bottino, C. J., Schmidt, M. E., et al. (2013). Healthy habits, happy homes: Randomized trial to improve household routines for obesity prevention among preschool aged children. JAMA Pediatrics, 167(11), 1072-1079.

Hales, C. N., \& Barker, D. J. (2001). The thrifty phenotype hypothesis. British Medical Bulletin, 60, 5-20.

Halfon, N., \& Forrest, C. B. (2017). The emerging theoretical framework of life course health development. In N. Halfon, C. B. Forrest, R. M. Lerner, \& E. Faustman (Eds.), Handbook of life course health-development science. Cham: Springer.

Harvey-Berino, J., \& Rourke, J. (2003). Obesity prevention in preschool native-American children: A pilot study using home visiting. Obesity Research, 11(5), 606-611.

Herbst, A., Kapellen, T., Schober, E., Graf, C., Meissner, T., \& Holl, R. (2014). Impact of regular physical activity on blood glucose control and cardiovascular risk factors in adolescents with type 2 diabetes mellitus a multicenter study of 578 patients from 225 centres. Pediatric Diabetes, 16(3), 204-210.

Hesketh, K. D., \& Campbell, K. J. (2010). Interventions to prevent obesity in 0-5 year olds: An updated systematic review of the literature. Obesity, 18(Supple 1), S27-S35.

Hirst, K., Baranowski, T., DeBar, L., Foster, G. D., Kaufman, F., Kennel, P., et al. (2009). HEALTHY study rationale, design and methods: Moderating risk of type 2 diabetes in multi-ethnic middle school students. International Journal of Obesity, 33(Suppl 4), S4-20.

Hiscock, H., Scalzo, K., Canterford, L., \& Wake, M. (2011). Sleep duration and body mass index in 0-7year olds. Archives of Disease in Childhood, 96(8), 735-739. 
Hoet, J. J., Dahri, S., Snoeck, A., Reusens-Billen, B., \& Remacle, C. (1992). Importance of diets and their effect on fetal development: Function and structure of the endocrine pancreas following protein deficiency during intrauterine life. Bulletin et Mémoires de l'Académie Royale de Médecine de Belgique, 147 (3-5), 174-181. discussion 81-83.

Imperatore, G., Boyle, J. P., Thompson, T. J., Case, D., Dabelea, D., Hamman, R. F., et al. (2012). Projections of type 1 and type 2 diabetes burden in the U.S. population aged <20 years through 2050: Dynamic modeling of incidence, mortality, and population growth. Diabetes Care, 35(12), 2515-2520.

ISPAD. (2011). Global IDF/ISPAD guideline for childhood and Pediatric diabetes. Brussels, Belgium: International Diabetes Foundation.

James, D. C., \& Lessen, R. (2009). Position of the American dietetic association: Promoting and supporting breastfeeding. Journal of the American Dietetic Association, 109(11), 1926-1942.

Jeffery, A. N., Metcalf, B. S., Hosking, J., Streeter, A. J., Voss, L. D., \& Wilkin, T. J. (2012). Age before stage: Insulin resistance rises before the onset of puberty: A 9-year longitudinal study (EarlyBird 26). Diabetes Care, 35(3), 536-541.

Johnson, C. L., \& Versalovic, J. (2012). The human microbiome and its potential importance to pediatrics. Pediatrics, 129(5), 950-960.

Kanaka-Gantenbein, C. (2010). Fetal origins of adult diabetes. Annals of the New York Academy of Sciences, 1205, 99-105.

Kapoor, A., Dunn, E., Kostaki, A., Andrews, M. H., \& Matthews, S. G. (2006). Fetal programming of hypothalamo-pituitary-adrenal function: Prenatal stress and glucocorticoids. The Journal of Physiology, 572(Pt 2), 31-44.

Katoh, S., Lehtovirta, M., Kaprio, J., Harjutsalo, V., Koskenvuo, M., Eriksson, J., et al. (2005). Genetic and environmental effects on fasting and postchallenge plasma glucose and serum insulin values in Finnish twins. Journal of Clinical Endocrinology and Metabolism, 90(5), 2642-2647.

Kaufman, F. R., Hirst, K., Linder, B., Baranowski, T., Cooper, D. M., Foster, G. D., et al. (2009). Risk factors for type 2 diabetes in a sixth-grade multiracial cohort: The HEALTHY study. Diabetes Care, 32(5), 953-955.

Kempf, K., Rathmann, W., \& Herder, C. (2008). Impaired glucose regulation and type 2 diabetes in children and adolescents. Diabetes/Metabolism Research and Reviews, 24, 427-437.

Kim, S. Y., England, J. L., Sharma, J. A., \& Njoroge, T. (2011). Gestational diabetes mellitus and risk of childhood overweight and obesity in offspring: A systematic review. Experimental Diabetes Research, 2011, 541308.

Kitzmann, K. M., Dalton, W. T., 3rd, Stanley, C. M., Beech, B. M., Reeves, T. P., et al. (2010). Lifestyle interventions for youth who are overweight: A metaanalytic review. Health Psychology, 29(1), 91-101.
Klingenberg, L., Christensen, L. B., Hjorth, M. F., Zangenberg, S., Chaput, J. P., Sjodin, A., et al. (2013). No relation between sleep duration and adiposity indicators in 9-36 months old children: The SKOT cohort. Pediatric Obesity, 8(1), e14-e18.

Knowlden, A. P., \& Sharma, M. (2012). Systematic review of family and home-based interventions targeting paediatric overweight and obesity. Obesity Reviews, 13(6), 499-508.

Koren, O., Goodrich, J. K., Cullender, T. C., Spor, A., Laitinen, K., Backhed, H. K., et al. (2012). Host remodeling of the gut microbiome and metabolic changes during pregnancy. Cell, 150(3), 470-480.

Kramer, M. S., Matush, L., Vanilovich, I., Platt, R. W., Bogdanovich, N., Sevkovskaya, Z., et al. (2009). A randomized breast-feeding promotion intervention did not reduce child obesity in Belarus. The Journal of Nutrition, 139(2), 417S-421S.

Lawrence, J., Mayer-Davis, E., Ryeynolds, K., Beyer, J., Pettitt, D., D’Agostino, R. B., et al. (2009a). Diabetes in Hispanic American youths. Diabetes Care, 32(Supplement 2), S123-S132.

Lawrence, J. M., Mayer-Davis, E. J., Reynolds, K., Beyer, J., Pettitt, D. J., D’Agostino, R. B., et al. (2009b). Diabetes in Hispanic American youth: Prevalence, incidence, demographics, and clinical characteristics: The SEARCH for diabetes in youth study. Diabetes Care, 32(Suppl 2), S123-S132.

Lee, Y. (2013). Diabetes care for emerging adults: Transition from pediatric to adult diabetes care systems. Annals of Pediatric Endocrinology \& Metabolism, 18, 106-110.

Ley, S. H., Hanley, A. J., Sermer, M., Zinman, B., \& O'Connor, D. L. (2012). Associations of prenatal metabolic abnormalities with insulin and adiponectin concentrations in human milk. The American Journal of Clinical Nutrition, 95(4), 867-874.

Li, R., Bilik, D., Brown, M. B., Zhang, P., Ettner, S. L., Ackerman, R. T., et al. (2013). Medical costs associated with type 2 diabetes complications and comorbidities. The American Journal of Managed Care, 19(5), 421-430.

Liu, L. L., Yi, J. P., Beyer, J., Mayer-Davis, E. J., Dolan, L. M., Dabelea, D. M., et al. (2009). Type 1 and type 2 diabetes in Asian and Pacific Islander U.S. youth: The SEARCH for diabetes in youth study. Diabetes Care, 32(Suppl 2), S133-S140.

Liu, J., Yu, P., Qian, W., Li, Y., Zhao, J., Huan, F., et al. (2013). Perinatal bisphenol a exposure and adult glucose homeostasis: Identifying critical windows of exposure. PloS One, 8(5), e64143.

Luepker, R. V., Perry, C. L., McKinlay, S. M., Nader, P. R., Parcel, G. S., Stone, E. J., et al. (1996). Outcomes of a field trial to improve children's dietary patterns and physical activity. The child and adolescent trial for cardiovascular health. CATCH collaborative group. The Journal of the American Medical Association, 275(10), 768-776.

Martin, R. M., Patel, R., Kramer, M. S., Vilchuck, K., Bogdanovich, N., Sergeichick, N., et al. (2014). Effects 
of promoting longer-term and exclusive breastfeeding on cardiometabolic risk factors at age 11.5 years: A cluster-randomized, controlled trial. Circulation, 129(3), 321-329.

Martin-Gronert, M. S., \& Ozanne, S. E. (2012). Mechanisms underlying the developmental origins of disease. Reviews in Endocrine \& Metabolic Disorders, 13(2), 85-92.

Maull, E. A., Ahsan, H., Edwards, J., Longnecker, M. P., Navas-Acien, A., Pi, J., et al. (2012). Evaluation of the association between arsenic and diabetes: A National Toxicology Program workshop review. Environmental Health Perspectives, 120(12), 1658-1670.

May, A. L., Kuklina, E. V., \& Yoon, P. W. (2012). Prevalence of cardiovascular disease risk factors among US adolescents, 1999-2008. Pediatrics, 129(6), 1035-1041.

Mayer-Davis, E. J., Rifas-Shiman, S. L., Zhou, L., Hu, F. B., Colditz, G. A., \& Gillman, M. W. (2006). Breastfeeding and risk for childhood obesity: Does maternal diabetes or obesity status matter? Diabetes Care, 29(10), 2231-2237.

Mayer-Davis, E. J., Dabelea, D., Lamichhane, A. P., D’Agostino, R. B., Jr., Liese, A. D., et al. (2008). Breast-feeding and type 2 diabetes in the youth of three ethnic groups: The SEARCh for diabetes in youth case-control study. Diabetes Care, 31(3), 470-475.

Mayer-Davis, E. J., Beyer, J., Bell, R. A., Dabelea, D., D’Agostino, R., Jr., Imperatorek, G., et al. (2009). Diabetes in African American youth: Prevalence, incidence, and clinical characteristics: The SEARCH for diabetes in youth study. Diabetes Care, 32(Supplement 2), S112-S122.

McEwen, B. S. (2008). Understanding the potency of stressful early life experiences on brain and body function. Metabolism Clinical and Experimental, 57(Suppl 2), S11-S15.

McLearn, K. T., Minkovitz, C. S., Strobino, D. M., Marks, E., \& Hou, W. (2006). Maternal depressive symptoms at 2 to 4 months post partum and early parenting practices. Archives of Pediatrics \& Adolescent Medicine, 160(3), 279-284.

McMillen, I. C., \& Robinson, J. S. (2005). Developmental origins of the metabolic syndrome: Prediction, plasticity, and programming. Physiological Reviews, 85(2), 571-633.

McMurray, R. G., Bassin, S., Jago, R., Bruecker, S., Moe, E. L., Murray, T., et al. (2009). Rationale, design and methods of the HEALTHY study physical education intervention component. International Journal of Obesity, 33(Suppl 4), S37-S43.

Meaney, M. J., Szyf, M., \& Seckl, J. R. (2007). Epigenetic mechanisms of perinatal programming of hypothalamic-pituitary-adrenal function and health. Trends in Molecular Medicine, 13(7), 269-277.

Metzger, B. E., Lowe, L. P., Dyer, A. R., Trimble, E. R., Chaovarindr, U., Coustan, D. R., et al. (2008). Hyperglycemia and adverse pregnancy outcomes.
The New England Journal of Medicine, 358(19), 1991-2002.

Metzger, B. E., Gabbe, S. G., Persson, B., Buchanan, T. A., Catalano, P. A., Damm, P., et al. (2010). International association of diabetes and pregnancy study groups recommendations on the diagnosis and classification of hyperglycemia in pregnancy. Diabetes Care, 33(3), 676-682.

Morandi, A., Maschio, M., Marigliano, M., Miraglia Del Giudice, E., Moro, B., Peverelli, P., et al. (2014). Screening for impaired glucose tolerance in obese children and adolescents: A validation and implementation study. Pediatric Obesity, 9(1), 17-25.

Morgan, A. R. (2012). Determining genetic risk factors for pediatric type 2 diabetes. Current Diabetes Reports, 12(1), 88-92.

Morris, D. H., Khunti, K., Achana, F., Srinivasan, B., Gray, L. J., Davies, M. J., et al. (2013). Progression rates from $\mathrm{HbA}(1 \mathrm{c}) 6.0-6.4 \%$ and other prediabetes definitions to type 2 diabetes: A meta-analysis. Diabetologia, 56(7), 1489-1493.

Morrison, K. M., Xu, L., Tarnopolsky, M., Yusuf, Z., Atkinson, S. A., \& Yusuf, S. (2012). Screening for dysglycemia in overweight youth presenting for weight management. Diabetes Care, 35(4), 711-716.

Moses, R. G. (2010). New consensus criteria for GDM: Problem solved or a pandora's box? Diabetes Care, 33(3), 690-691.

Navas-Acien, A., Silbergeld, E. K., Pastor-Barriuso, R., \& Guallar, E. (2008). Arsenic exposure and prevalence of type 2 diabetes in US adults. JAMA, 300(7), 814-822.

Neville, M. C., Anderson, S. M., McManaman, J. L., Badger, T. M., Bunik, M., Contractor, N., et al. (2012). Lactation and neonatal nutrition: Defining and refining the critical questions. Journal of Mammary Gland Biology and Neoplasia, 17(2), 167-188. doi:10.1007/ s10911-012-9261-5.

Ong, K. K. (2010). Early determinants of obesity. Endocrine Development, 19, 53-61.

Pervanidou, P., \& Chrousos, G. P. (2011). Stress and obesity/metabolic syndrome in childhood and adolescence. International Journal of Pediatric Obesity, 6(Supplement 1), 21-28.

Pervanidou, P., \& Chrousos, G. P. (2012). Metabolic consequences of stress during childhood and adolescence. Metabolism, 61(5), 611-619.

Peters, A., \& Laffel, L. (2011). Diabetes care for emerging adults: Recommendations for transition from pediatric to adult diabetes care systems: A position statement of the American Diabetes Association. Diabetes Care, 34(11), 2477-2485.

Plagemann, A., Harder, T., Franke, K., \& Kohlhoff, R. (2002). Long-term impact of neonatal breast-feeding on body weight and glucose tolerance in children of diabetic mothers. Diabetes Care, 25(1), 16-22.

Prince, A. L., Antony, K. M., Ma, J., \& Aagaard, K. M. (2014). The microbiome and development: A mother's perspective. Seminars in Reproductive Medicine, 32(1), 14-22. 
Raman, A., Ritchie, L. D., Lustig, R. H., Fitch, M. D., Hudes, M. L., \& Fleming, S. E. (2010). Insulin resistance is improved in overweight African American boys but not in girls following a one-year multidisciplinary community intervention program. Journal of Pediatric Endocrinology \& Metabolism, 23(1-2), 109-120.

Rhodes, E. T., Prosser, L. A., Hoerger, T. J., Lieu, T., Ludwig, D. S., \& Laffel, L. M. (2012). Estimated morbidity and mortality in adolescents and young adults diagnosed with type 2 diabetes mellitus. Diabetic Medicine, 29(4), 453-463.

Ritchie, L. D., Sharma, S., Ikeda, J. P., Mitchell, R. A., Raman, A., Green, B. S., et al. (2010). Taking action together: A YMCA-based protocol to prevent type-2 diabetes in high-BMI inner-city African American children. Trials, 11, 60.

Robinson, S., Ntani, G., Simmonds, S., Syddall, H., Dennison, E., Sayer, A. A., et al. (2013). Type of milk feeding in infancy and health behaviours in adult life: Findings from the Hertfordshire cohort study. The British Journal of Nutrition, 109(6), 1114-1122.

Rolland-Cachera, M. F. (2011). Childhood obesity: Current definitions and recommendations for their use. International Journal of Pediatric Obesity, 6(56), 325-331.

Rosenbaum, M., Nonas, C., Weil, R., Horlick, M., Fennoy, I., Vargas, I., et al. (2007). School-based intervention acutely improves insulin sensitivity and decreases inflammatory markers and body fatness in junior high school students. The Journal of Clinical Endocrinology and Metabolism, 92(2), 504-508.

Rosenbloom, A. L., Joe, J. R., Young, R. S., \& Winter, W. E. (1999). Emerging epidemic of type 2 diabetes in youth. Diabetes Care, 22(2), 345-354.

Rosenbloom, A. L., Silverstein, J. H., Amemiya, S., Zeitler, P., \& Klingensmith, G. J. (2008). ISPAD clinical practice consensus guidelines 2006-2007. Type 2 diabetes mellitus in the child and adolescent. Pediatric Diabetes, 9(5), 512-526.

Saelens, B. E., Grow, H. M., Stark, L. J., Seeley, R. J., \& Roehrig, H. (2011). Efficacy of increasing physical activity to reduce children's visceral fat: A pilot randomized controlled trial. International Journal of Pediatric Obesity, 6(2), 102-112.

Salsberry, P. J., \& Reagan, P. B. (2005). Dynamics of early childhood overweight. Pediatrics, 116(6), 1329-1338

Samuelsson, A. M., Matthews, P. A., Argenton, M., Christie, M. R., McConnell, J. M., et al. (2008). Dietinduced obesity in female mice leads to offspring hyperphagia, adiposity, hypertension, and insulin resistance: A novel murine model of developmental programming. Hypertension, 51(2), 383-392.

Savoye, M., Shaw, M., Dziura, J., Tamborlane, W. V., Rose, P., Guandalini, C., et al. (2007). Effects of a weight management program on body composition and metabolic parameters in overweight children: A randomized controlled trial. JAMA, 297(24), 2697-2704.
Savoye, M., Nowicka, P., Shaw, M., Yu, S., Dziura, J., Chavent, G., et al. (2011). Long-term results of an obesity program in an ethnically diverse pediatric population. Pediatrics, 127(3), 402-410.

Savoye, M., Caprio, S., Dziura, J., Camp, A., Germain, G., Summers, C., et al. (2014). Reversal of early abnormalities in glucose metabolism in obese youth: Results of an intensive lifestyle randomized controlled trial. Diabetes Care, 37(2), 317-324.

Schore, A. N. (2005). Back to basics: Attachment, affect regulation, and the developing right brain: Linking developmental neuroscience to pediatrics. Pediatrics in Review, 26(6), 204-217.

Sebert, S., Sharkey, D., Budge, H., \& Symonds, M. E. (2011). The early programming of metabolic health: Is epigenetic setting the missing link? The American Journal of Clinical Nutrition, 94(6 Supplement), 1953S-1958S.

Seki, Y., Williams, L., Vuguin, P. M., \& Charron, M. J. (2012). Minireview: Epigenetic programming of diabetes and obesity: Animal models. Endocrinology, 153(3), 1031-1038.

Shaw, J. E., Socree, R. A., \& Zimmet, P. Z. (2010). Global estimates of the prevalence of diabetes for 2010 and 2030. Diabetes Research and Clinical Practice, 87, 4-14.

Shonkoff, J. P., \& Garner, A. S. (2012). The lifelong effects of early childhood adversity and toxic stress. Pediatrics, 129(1), e232-e246.

Silverman, B. L., Rizzo, T. A., Cho, N. H., \& Metzger, B. E. (1998). Long-term effects of the intrauterine environment. The Northwestern University diabetes in pregnancy Center. Diabetes Care, 21(Suppl 2), B142-B149.

Simeoni, U., \& Barker, D. J. (2009). Offspring of diabetic pregnancy: Long-term outcomes. Seminars in Fetal \& Neonatal Medicine, 14(2), 119-124.

Sinclair, K. D., Lea, R. G., Rees, W. D., \& Young, L. E. (2007). The developmental origins of health and disease: Current theories and epigenetic mechanisms. Society of Reproduction and Fertility Supplement, 64, 425-443.

Sinha, R., Fisch, G., Teague, B., Tamborlane, W. V., Banyas, B., Allen, K., et al. (2002). Prevalence of impaired glucose tolerance among children and adolescents with marked obesity. The New England Journal of Medicine, 346(11), 802-810.

Skouteris, H., McCabe, M., Swinburn, B., Newgreen, V., Sacher, P., \& Chadwick, P. (2011). Parental influence and obesity prevention in pre-schoolers: A systematic review of interventions. Obesity Reviews, 12(5), 315-328.

Skouteris, H., McCabe, M., Ricciardelli, L., Milgrom, J., Baur, L., Aksan, N., et al. (2012). Parent-child interactions and obesity prevention: A systematic review of the literature. Early Child Development and Care, 182(2), 153-174.

Smith, B. T., Lynch, J. W., Fox, C. S., Harper, S., Abrahamowicz, M., Almeida, N. D., et al. (2011). Life-course socioeconomic position and type 2 dia- 
betes mellitus: The Framingham offspring study. American Journal of Epidemiology, 173(4), 438-447.

Snieder, H., Boomsma, D. I., van Doornen, L. J., \& Neale, M. C. (1999). Bivariate genetic analysis of fasting insulin and glucose levels. Genetic Epidemiology, 16(4), 426-446.

Stark, L. J., Clifford, L. M., Towner, E. K., Filigno, S. S., Zion, C., Bolling, C., et al. (2014). A pilot randomized controlled trial of a behavioral familybased intervention with and without home visits to decrease obesity in preschoolers. Journal of Pediatric Psychology, 39(9), 1001-1012. doi:10.1093/jpepsy/ jsu059.

Szajewska, H. (2013). Microbiota modulation: Can probiotics prevent/treat disease in pediatrics? Nestle Nutrition Institute Workshop Series, 77, 99-110.

Tamayo, T., Christian, H., \& Rathmann, W. (2010). Impact of early psychosocial factors (childhood socioeconomic factors and adversities) on future risk of type 2 diabetes, metabolic disturbances and obesity: A systematic review. BMC Public Health, 10, 525. doi:10.1186/1471-2458-10-525.

Tamayo, T., Jacobs, D. R., Jr., Strassburger, K., Giani, G., Seeman, T. E., Matthews, K., et al. (2012). Race- and sex-specific associations of parental education with insulin resistance in middle-aged participants: The CARDIA study. European Journal of Epidemiology, 27(5), 349-355.

Tarry-Adkins, J. L., \& Ozanne, S. E. (2011). Mechanisms of early life programming: Current knowledge and future directions. The American Journal of Clinical Nutrition, 94(6 Supplement), 1765S-1771S.

Taveras, E. M., Scanlon, K. S., Birch, L., Rifas-Shiman, S. L., Rich-Edwards, J. W., \& Gillman, M. W. (2004). Association of breastfeeding with maternal control of infant feeding at age 1 year. Pediatrics, 114(5), e577-e583.

Taveras, E. M., Rifas-Shiman, S. L., Oken, E., Gunderson, E. P., \& Gillman, M. W. (2008). Short sleep duration in infancy and risk of childhood overweight. Archives of Pediatrics \& Adolescent Medicine, 162(4), 305-311.

Taveras, E. M., Gillman, M. W., Pena, M. M., Redline, S., \& Rifas-Shiman, S. L. (2014). Chronic sleep curtailment and adiposity. Pediatrics, 133(6), 1013-1022.

Thayer, K. A., Heindel, J. J., Bucher, J. R., \& Gallo, M. A. (2012). Role of environmental chemicals in diabetes and obesity: A National Toxicology Program workshop review. Environmental Health Perspectives, 120(6), 779-789.

Thompson, A. L., \& Bentley, M. E. (2013). The critical period of infant feeding for the development of early disparities in obesity. Social Science \& Medicine, 97, 288-296.

Tounian, P. (2011). Programming towards childhood obesity. Annals of Nutrition \& Metabolism, 58(Suppl 2), 30-41.

Trevino, R. P., Yin, Z., Hernandez, A., Hale, D. E., Garcia, O. A., \& Mobley, C. (2004). Impact of the Bienestar school-based diabetes mellitus prevention program on fasting capillary glucose levels: A randomized controlled trial. Archives of Pediatrics \& Adolescent Medicine, 158(9), 911-917.

Venditti, E. M., Elliot, D. L., Faith, M. S., Firrell, L. S., Giles, C. M., Goldberg, L., et al. (2009). Rationale, design and methods of the HEALTHY study behavior intervention component. International Journal of Obesity, 33(Suppl 4), S44-S51.

Venkat Narayan, K. M., Boyle, J. P., Thompson, T. J., Sorensen, S. W., \& Willimason, D. F. (2003). Lifetime risk for riabetes mellitus in the United States. JAMA, 290(14), 1884-1889.

Versalovic, J. (2013). The human microbiome and probiotics: Implications for pediatrics. Annals of Nutrition \& Metabolism, 63(Suppl 2), 42-52.

Visscher, P. M., Hill, W. G., \& Wray, N. R. (2008). Heritability in the genomics era-concepts and misconceptions. Nat Rev Genet, 9(4), 255-266.

Wabitsch, M., Hauner, H., Hertrampf, M., Muche, R., Hay, B., Mayer, H., et al. (2004). Type II diabetes mellitus and impaired glucose regulation in Caucasian children and adolescents with obesity living in Germany. International Journal of Obesity and Related Metabolic Disorders, 28(2), 307-313.

Waitzfelder, B., Pihoker, C., Klingensmith, G., Case, D., Anderson, A., Bell, R. A., et al. (2011). Adherence to guidelines for youths with diabetes mellitus. Pediatrics, 128(3), 531-538.

Wang, L., Anderson, J. L., Dalton, W. T., Wu, T., Liu, X., \& Zheng, S. (2013). Maternal depressive symptoms and the risk of overweight in their children. Maternal and Child Health Journal, 17(5), 940-948.

Warner, M. J., \& Ozanne, S. E. (2010). Mechanisms involved in the developmental programming of adulthood disease. The Biochemical Journal, 427(3), 333-347.

Weiss, R., Taksali, S. E., Tamborlane, W. V., Burgert, T. S., Savoye, M., \& Caprio, S. (2005). Predictors of changes in glucose tolerance status in obese youth. Diabetes Care, 28(4), 902-909.

Wen, L. M., Baur, L. A., Simpson, J. M., Rissel, C., Wardle, K., \& Flood, V. M. (2012). Effectiveness of home based early intervention on children's BMI at age 2: Randomised controlled trial. BMJ, 344, e3732. doi:10.1136/bmj.e3732.

West, N. A., Hamman, R. F., Mayer-Davis, E. J., D’Agostino, R. B., Jr., Marcovina, S. M., Liese, A. S., et al. (2009). Cardiovascular risk factors among youth with and without type 2 diabetes: Differences and possible mechanisms. Diabetes Care, 32(1), 175-180.

Whitlock, E. P., O’Connor, E. A., Williams, S. B., Beil, T. L., \& Lutz, K. W. (2010). Effectiveness of weight management interventions in children: A targeted systematic review for the US preventive service task Force. Pediatrics, 125(2), e396-e418.

Whitmore, T. J., Trengove, N. J., Graham, D. F., \& Hartmann, P. E. (2012). Analysis of insulin in human breast milk in mothers with type 1 and type 2 diabetes mellitus. International Journal of Endocrinology, 2012, 296368. doi:10.1155/2012/296368. 
Zeitler, P. (2010). Approach to the obese adolescent with new-onset diabetes. The Journal of Clinical Endocrinology and Metabolism, 95(12), 5163-5170.

Zeitler, P., Hirst, K., Pyle, L., Linder, B., Copeland, K., Arslanian, S., et al. (2012). A clinical trial to maintain glycemic control in youth with type 2 diabetes. New England Journal of Medicine, 366(24), 2247-2256.

Zeitler, P., Tandon, N., Nadeau, K., Urakami, T., Barrett, T., \& Maahs, D. (2014). Type 2 diabetes in the child and adolescent. Pediatric Diabetes, 20(Supplement), 20-26.

Open Access This chapter is licensed under the terms of the Creative Commons Attribution 4.0 International License (http://creativecommons.org/licenses/by/4.0/), which permits use, sharing, adaptation, distribution and reproduction in any medium or format, as long as you give appropriate credit to the original author(s) and the source, provide a link to the Creative Commons license and indicate if changes were made.

The images or other third party material in this chapter are included in the chapter's Creative Commons license, unless indicated otherwise in a credit line to the material. If material is not included in the chapter's Creative Commons license and your intended use is not permitted by statutory regulation or exceeds the permitted use, you will need to obtain permission directly from the copyright holder. 